\title{
Impacts of a Groundwater Scheme on Hydroclimatological Conditions over Southern South America ${ }^{\circ}$
}

\author{
J. Alejandro MARTineZ ${ }^{\mathrm{a}}$ \\ Department of Atmospheric Sciences, University of Arizona, Tucson, Arizona \\ FRANCINA DOMINGUEZ \\ Department of Atmospheric Sciences, University of Illinois at Urbana-Champaign, Urbana, Illinois \\ GonZALO MigueZ-MACHO \\ Faculty of Physics, Universidad de Santiago de Compostela, Galicia, Spain
}

(Manuscript received 26 February 2016, in final form 26 July 2016)

\begin{abstract}
A sensitivity study of the impact of a groundwater scheme on hydrometeorological variables in coupled land-atmosphere simulations over southern South America is presented. It is found that shallow water tables in the groundwater scheme lead to reduced drainage and even upward capillary fluxes over parts of the central and southern La Plata basin. This leads to an increase in the simulated moisture in the root zone, which in turn produces an increase in evapotranspiration (ET) over the southern part of the domain, where ET is water limited. There is also a decrease in the near-surface temperature, in the range $0.5^{\circ}-1.0^{\circ} \mathrm{C}$. During the dry season, the increases in ET and relative humidity over the central La Plata coincide with an increase in precipitation downstream. Including groundwater leads to an increase in precipitation over parts of the central and southern La Plata basin during the early rainy season (October-December). The overall increase in ET and precipitation over the southern La Plata basin during the early rainy season is $13 \%$ and $10 \%$, respectively. The additional precipitation comes from both an increase in the availability of atmospheric moisture when the groundwater scheme is used and its effect on the atmospheric instability. In the La Plata basin, including a representation of groundwater increases simulated precipitation and partially alleviates a warm and dry bias present in simulations without realistic subsurface hydrology.
\end{abstract}

\section{Introduction}

Land surface conditions and soil moisture patterns play an important role on local and regional climates (e.g., Betts 2004, 2009; Pielke 2001; Cotton and Pielke 2007; Seneviratne et al. 2010). Betts (2009) finds a tendency to an increase in precipitation when the relative humidity

Supplemental information related to this paper is available at the Journals Online website: http://dx.doi.org/10.1175/ JHM-D-16-0052.s1.

${ }^{\text {a }}$ Current affiliation: Institute of Physics, University of Antioquia, Medellin, Colombia.

Corresponding author address: Francina Dominguez, Department of Atmospheric Sciences, University of Illinois at Urbana-Champaign, 105 S. Gregory St., Urbana, IL 61801-3070.

E-mail: francina@illinois.edu
(RH) near the surface is higher due to enhanced evapotranspiration (ET), which in turn produces a lower lifting condensation level (LCL) and favorable conditions for the development of instabilities in the atmosphere. However, Pan et al. (1996) suggest that the increase in ET might enhance precipitation if the convective boundary layer is already relatively dry and well developed. This suggestion is supported by the study by Findell and Eltahir (2003), who find that even over wet soils the probability of precipitation is low if the atmosphere is very stable. Findell and Eltahir (2003) also find that convective precipitation develops over both wet and dry soils under similar instability conditions, with larger precipitation amounts over wet soils. In a modeling study, Schär et al. (1999) describe how an increase in soil moisture can lead to an increase in precipitation via several and possibly simultaneous mechanisms, including 
the increase of moisture in the atmosphere from enhanced ET, the increase of moist static energy (MSE) in the lower levels and the ensuing increase in convective instability, and the decrease of radiative cooling of the surface, which further increases the moist entropy flux into the boundary layer. As shown by Findell and Eltahir (2003), the sign of the feedback between soil moisture and precipitation depends on different factors, including the moisture available at low levels, the atmospheric stability, and the large-scale circulation.

The role of soil moisture in the evolution of atmospheric conditions has been found to be important for the weather and climate of South America. In a modeling study, de Goncalves et al. (2006b) obtain improved 7-day weather simulations when more realistic soil moisture fields are used as initial conditions as opposed to mean climatological estimates. Saulo et al. (2010) found a larger sensitivity in the 10-day forecasts of precipitation for a low pressure event over Argentina when drier initial conditions were used for the soil moisture field. Doyle et al. (2013) obtain an improvement in the simulation of a mesoscale convective system over northern Argentina by updating the map of soil properties and improving the initial condition of the soil moisture field. At the seasonal time scale, Collini et al. (2008) find that during the early stages of the South American monsoon, precipitation over the South American monsoon region is more sensitive to dry soil moisture anomalies, showing a decrease in precipitation due to reduced moisture contribution from both local and upstream sources. Sörensson and Berbery (2015) find that seasonal regional simulations are better initialized during the wet season (September-February), when the difference between the initial soil moisture and the equilibrium state of the model is smaller. In general, regions within and in the vicinity of the La Plata basin have been considered a hot spot for landatmosphere feedbacks (e.g., Dirmeyer et al. 2009b), which exhibit a positive and substantial feedback between soil moisture and precipitation (e.g., Zeng et al. 2010; Sörensson and Menéndez 2011; Spenneman and Saulo 2015).

Shallow unconfined aquifers are a fundamental component of the hydrologic cycle that may affect the soil moisture content in the layers close to the surface, including the root zone (Fan et al. 2013; Fan 2015). Kuppel et al. (2015) show how the shallow water tables (1-3 m deep) in the Argentinean Pampas are strongly coupled with the variations in the terrestrial water storage (TWS), which in turn is highly correlated with ET over the region. Using data from the Global Land Data Assimilation System (GLDAS), Chen et al. (2010) find a trend in TWS closer to observations from the Gravity
Recovery and Climate Experiment (GRACE) when they combine the original model output (from the Noah model, which does not include a representation of the groundwater) with groundwater storage data from wells within the southern La Plata basin. Several modeling studies have shown that a representation of groundwater dynamics within models for weather and climate studies can substantially affect the simulation of soil moisture and evapotranspiration over South America (e.g., Niu et al. 2007; Miguez-Macho and Fan 2012; Koirala et al. 2014). In particular, the La Plata basin is one of the regions where the groundwater impact on other simulated hydrologic variables is expected to be larger, as the estimated water table is relatively shallow over this region (e.g., Fan and Miguez-Macho 2010; Fan et al. 2013). This is consistent with the physical picture provided by observations, as suggested by the studies from Kuppel et al. (2015) and Chen et al. (2010).

Modeling studies over the United States suggest that the increase in ET and soil moisture induced by groundwater schemes can in turn modify near-surface conditions such as 2-m temperature and the patterns of precipitation (Anyah et al. 2008; Jiang et al. 2009; Barlage et al. 2015). Given the strong coupling between soil moisture and precipitation over southern South America, and the impact of groundwater schemes on the simulation of soil moisture and evapotranspiration, we expect a stronger effect of a groundwater scheme on simulated near-surface conditions and precipitation over the region.

In a companion paper (Martinez et al. 2016), we conducted offline simulations (i.e., with prescribed atmospheric conditions) with Noah-MP (Niu et al. 2011) and the groundwater scheme developed by MiguezMacho et al. (2007). We found an increase in the simulated moisture in the root zone and on ET over parts of the La Plata basin and the southern Amazon. Here we extend our previous work by studying two fully coupled land-atmosphere simulations with the Weather Research and Forecasting (WRF) Model: using Noah-MP with and without the groundwater scheme developed by Miguez-Macho et al. (2007). In this study we focus on the effects of the groundwater scheme on the simulation of some hydrometeorological variables over southern South America, including near-surface temperature and precipitation.

\section{Methodology}

\section{a. Model configuration}

The modeling system used in this study is WRF, version 3.4.1 (Skamarock et al. 2008). The model domain includes the La Plata basin and most of the 
Terrain Height (m)

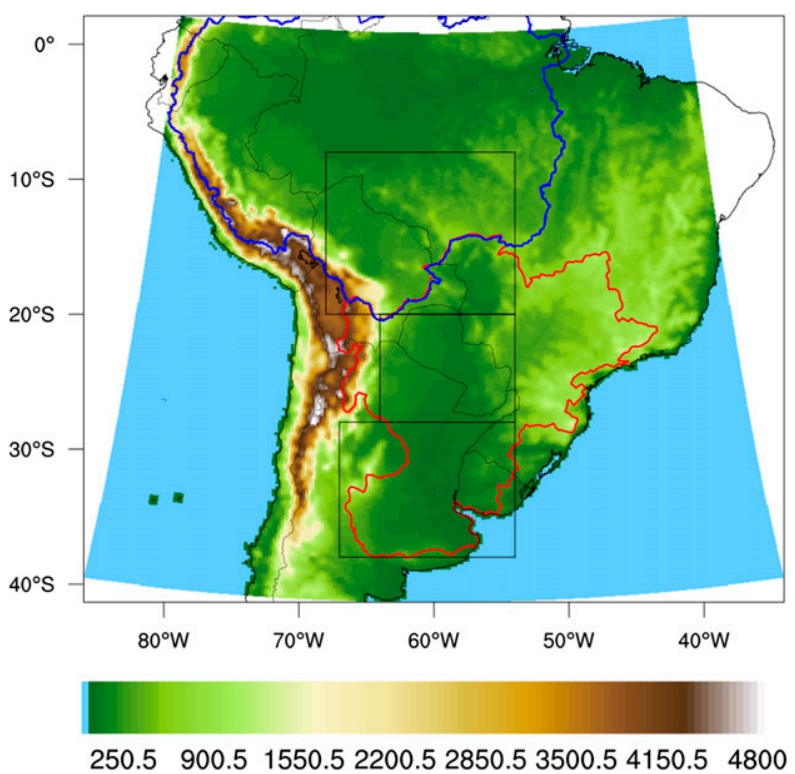

FIG. 1. Model domain and definition of regions of interest. Red (blue) contour represents the La Plata (Amazon) basin. The upper box is used to represent the southern Amazon, the middle box is used to represent the central La Plata basin, and the lower box is used to represent the southern La Plata basin.

Amazon basin (Fig. 1). Three boxes are drawn and used throughout the text to broadly represent the "southern Amazon" $\left(20^{\circ}-8^{\circ} \mathrm{S}, 68^{\circ}-54^{\circ} \mathrm{W}\right)$, the "central part of the La Plata basin" (UPLP; $28^{\circ}-20^{\circ} \mathrm{S}, 64^{\circ}-54^{\circ} \mathrm{W}$ ), and the "southern La Plata basin" (LOLP; $38^{\circ}-28^{\circ} \mathrm{S}, 67^{\circ}-54^{\circ} \mathrm{W}$ ). Some details of the configuration of the model are shown in Table 1. The physical parameterizations are the same as in previous studies of the hydrometeorology of the La Plata basin, which have provided a consistent representation of the temperature and precipitation fields over southern South America (Lee and Berbery 2012; Lee et al. 2013; Müller et al. 2014; Sörensson and Berbery 2015). Spectral nudging is used in the simulations, forcing wavelengths of $1467 \mathrm{~km}$ (wavenumber 3) and longer, similar to Lee et al. (2013). The goal is to preserve characteristics of the large-scale circulation (Miguez-Macho et al. 2004), while allowing for the development of perturbations at smaller scales due to the land-atmosphere interactions. In addition, we extended the soil column to a depth of $4 \mathrm{~m}$ and divided it into 14 layers, according to the configuration used by MiguezMacho and Fan (2012). In this configuration, the top $2 \mathrm{~m}$ of the soil column (which is the root zone in the model) contains 10 layers, instead of the default four layers of the Noah-MP and Noah LSMs. Having more layers in the top of the soil column is necessary because of the larger gradients near the surface. Although having
TABLE 1. Model configuration options.

\begin{tabular}{ll}
\hline \multicolumn{1}{c}{ Option } & \multicolumn{1}{c}{ Model configuration } \\
\hline Microphysics & WSM6 \\
Longwave radiation scheme & RRTM \\
Shortwave radiation scheme & Dudhia \\
Surface layer & Monin-Obukhov (Janjić) \\
Planetary boundary layer & Mellor-Yamada-Janjić \\
Cumulus convection & Betts-Miller-Janjić \\
Land surface model & Noah-MP \\
Horizontal grid size & 20 km \\
Vertical levels & 39 \\
Soil layers & 14, bottom at 4 m below \\
& ground level \\
Bottom boundary condition & FD (opt_run $=3$ ), \\
& GW(opt_run $=5)$ \\
\hline
\end{tabular}

deeper soil would be ideal, the 4-m-deep soil column is a compromise between including shallow water tables in the resolved soil column and computational constraints. When the water table is deeper than $4 \mathrm{~m}$, an additional layer is added between the bottom of the resolved soil column and the water table (see Miguez-Macho et al. 2007). The configuration of Noah-MP is the same as used in a companion paper (Martinez et al. 2016).

The horizontal grid size is $20 \mathrm{~km}$, at which we can resolve potential land surface effects due to contrasts at the mesoscale while maintaining computational efficiency for these continental-scale simulations. This grid size $(20 \mathrm{~km})$ is similar to that used in recent process studies over the region of interest [between 12 and $36 \mathrm{~km}$ in Lee and Berbery (2012), Müller et al. (2014), and Sörensson and Berbery (2015)], and it represents a higher resolution compared with recent climate simulations for South America $[\sim 50 \mathrm{~km}$ in Solman et al. (2013)]. The period of simulation is from 1 January 2006 to 31 December 2009 (4 years). The analysis of de Goncalves et al. (2006a) suggests that the spinup time for soil moisture in the region of interest is between 12 and 18 months. On the other hand, Sörensson and Berbery (2015) found that the skill in seasonal predictions improves if the model is initialized during the wet season September-February. This suggests that the spinup time could be reduced by starting the simulations during the wet season. Therefore, we initialize the model during the wet season (January), and we run continuous simulations for four years. Initial conditions for the water table are derived from equilibrium simulations that use 30-yr averages of recharge (Fan and Miguez-Macho 2010). After the first few months of simulation, no systematic trends are observed. In addition, the soil states and the effects of the groundwater scheme observed during and after the first simulated dry season (June-August 2006) are very similar to those 
observed in 10-yr-long simulations (with 30 years of spinup) using prescribed atmospheric conditions, as obtained in our companion paper (Martinez et al. 2016). Because of the nearly stationary characteristics of the present coupled simulations and their similitude to our multidecadal offline simulations, we exclude only the first 5 months from the present analysis.

The groundwater scheme used in this study [hereafter the Miguez-Macho and Fan (MMF) groundwater scheme] was developed by Miguez-Macho et al. (2007). More recently, the MMF scheme was implemented in the Noah-MP land surface model as one of the "runoff" options (Barlage et al. 2015). The MMF groundwater scheme includes a representation of a shallow aquifer and its interaction with the soil column above. The groundwater storage in each grid cell of the aquifer is determined by the balance between the vertical flux to/from the unsaturated soil layers, the lateral fluxes with its eight nearest coplanar neighbors, and subsurface runoff (Miguez-Macho et al. 2007). The MMF groundwater scheme has been previously used in several studies using offline simulations (e.g., MiguezMacho et al. 2007; Miguez-Macho and Fan 2012) and in coupled land-atmosphere simulations (e.g., Anyah et al. 2008; Barlage et al. 2015). In the present study, fully coupled land-atmosphere simulations with the MMF groundwater scheme are compared with simulations that have free drainage as boundary condition at the bottom of the soil column in order to assess the effects of the groundwater scheme on soil moisture, evapotranspiration, near-surface conditions, and precipitation over southern South America. We will refer to the simulations with the MMF groundwater scheme as the GW simulations, and to those with the free drainage bottom boundary condition as FD simulations. The slope parameter in the FD simulations has been changed from its default value of 0.1 (i.e., drainage only at $10 \%$ of the value determined by gravity and hydraulic conductivity) to 1.0 (i.e., full drainage according to gravity and hydraulic conductivity), in order to assess the full effect of the groundwater scheme. The initial conditions of the water-table depth, and the parameters of the groundwater scheme, were obtained by Fan and Miguez-Macho (2010), assuming equilibrium conditions among long-term estimates of evapotranspiration, precipitation, runoff, and the lateral flow of groundwater over South America.

\section{b. Diagnostic variables}

We use measures of the LCL, the maximum convective available potential energy (MCAPE), and the maximum convective inhibition (MCIN), as estimated for an air parcel with the largest equivalent potential temperature in the lowest $3 \mathrm{~km}$ of the atmosphere, to quantify the effects of the near-surface changes on the atmospheric structure and stability (see NCAR Command Language documentation at https://www.ncl.ucar. edu). While these diagnostics are unable to synthesize all the complexity of the vertical structure of the simulated atmosphere, and the corresponding details leading to stable or unstable conditions, an analysis of the LCL, MCAPE, and MCIN is useful in the interpretation of the potential mechanisms behind the changes in precipitation from our simulations. These diagnostics have been also used in previous studies (e.g., Lee and Berbery 2012; Lee et al. 2013).

\section{c. Comparison to observations}

We compare near-surface temperature and precipitation from the FD simulations with two reference datasets to identify some of the biases of our WRF simulations. For temperature, we use the Climatic Research Unit time series, version 3.21 (CRU TS3.21), product (Jones and Harris 2013), and for precipitation the TRMM 3B43 product (Huffman et al. 2007; Huffman and Bolvin 2014). The averages during the June-August (JJA) and October-December (OND) seasons throughout the 2006-09 period are shown in Figs. 2 and 3 for temperature and precipitation, respectively. The temperature fields in the FD simulation are in general similar to those from the CRU during both seasons (Fig. 2). WRF tends to underestimate near-surface temperatures over northwestern Brazil in both seasons. During JJA, the FD simulation produces higher temperatures over the southern La Plata basin. During OND, the FD run also tends to simulate higher temperatures over both the central and southern La Plata. The overall seasonal patterns and changes in precipitation are also well represented by WRF (Fig. 3). During JJA, the FD simulation tends to underestimate precipitation over northern Bolivia, southern Brazil, and Uruguay. Solman et al. (2013) find a similar bias when comparing observations with seven simulations that follow the protocol from the Coordinated Regional Climate Downscaling Experiment (CORDEX; see their Fig. 3c). During OND, the FD simulation underestimates precipitation over the central and southern La Plata basin. The spatial location of this bias is similar to that reported by Solman et al. (2013) for the DJF season (see their Fig. 3f).

WRF exhibits biases in different variables over South America (e.g., Ruiz et al. 2010; Lee 2010), likely due to problems with different components of the model, as is the general case for different regional climate models (RCMs) over the region (e.g., Solman et al. 2013). For 
CRU TS3.21 TMP $\left({ }^{\circ} \mathrm{C}\right)$, JJA

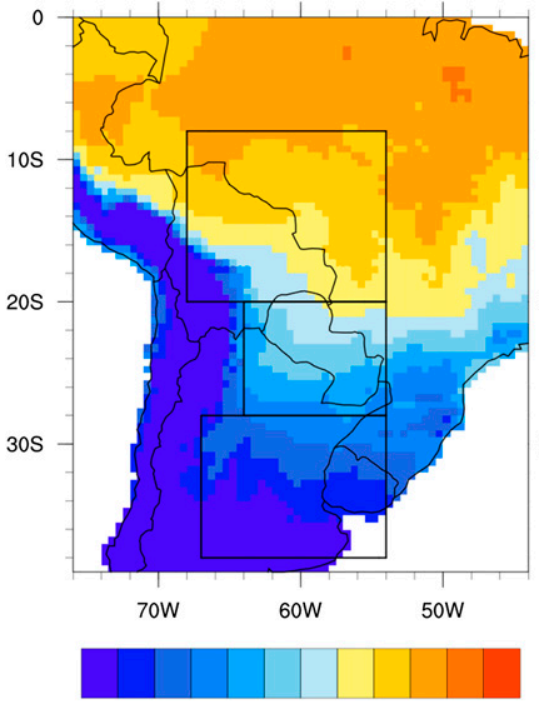

$\begin{array}{lllllllllll}10 & 12 & 14 & 16 & 18 & 20 & 22 & 24 & 26 & 28 & 30\end{array}$

CRU TS3.21 TMP $\left({ }^{\circ} \mathrm{C}\right)$, OND

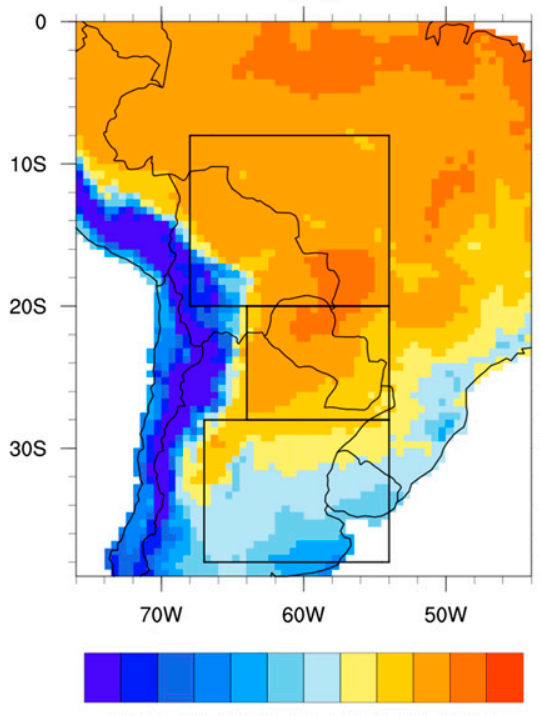

$\begin{array}{lllllllllll}10 & 12 & 14 & 16 & 18 & 20 & 22 & 24 & 26 & 28 & 30\end{array}$
FD T2m $\left({ }^{\circ} \mathrm{C}\right)$, JJA

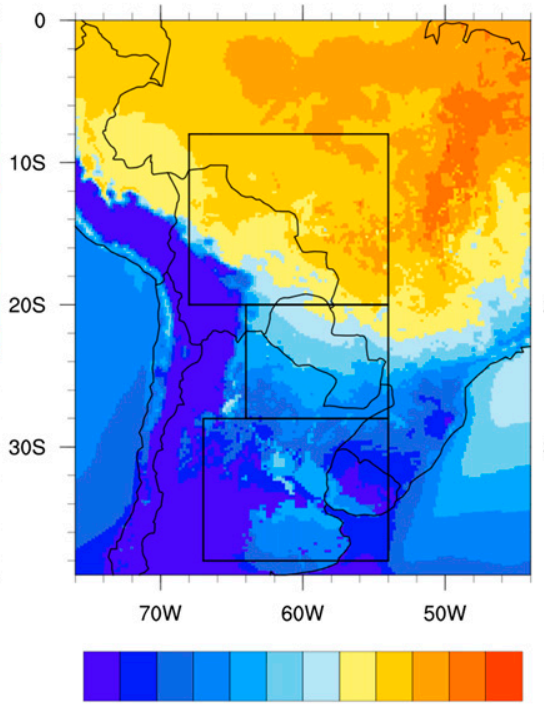

$\begin{array}{lllllllllll}10 & 12 & 14 & 16 & 18 & 20 & 22 & 24 & 26 & 28 & 30\end{array}$

FD T2m $\left({ }^{\circ} \mathrm{C}\right)$, OND

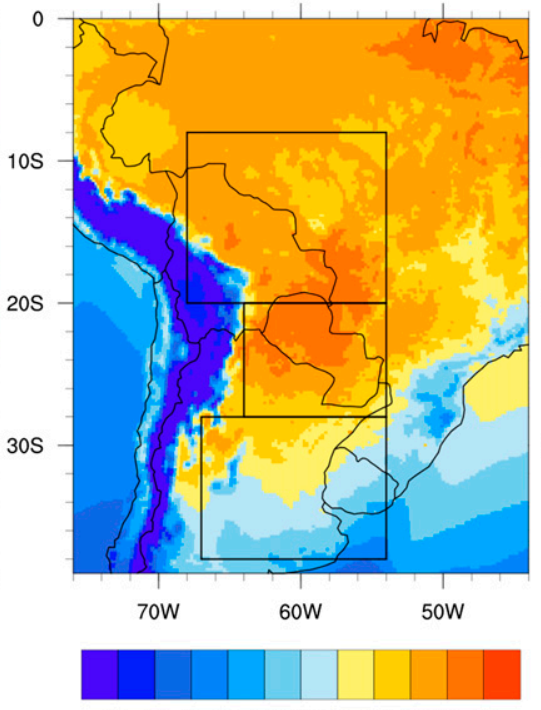

$\begin{array}{lllllllllll}10 & 12 & 14 & 16 & 18 & 20 & 22 & 24 & 26 & 28 & 30\end{array}$
FD-CRU TS3.21 TMP $\left({ }^{\circ} \mathrm{C}\right)$, JJA

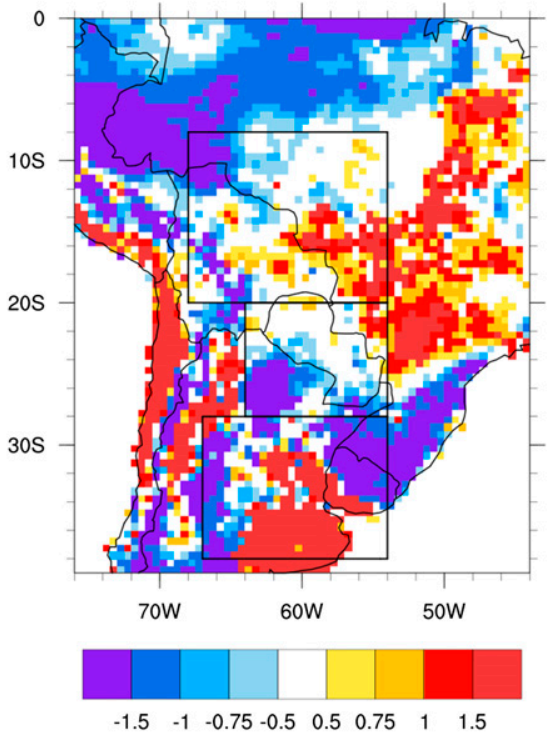

FD-CRU TS3.21 TMP $\left({ }^{\circ} \mathrm{C}\right)$, OND

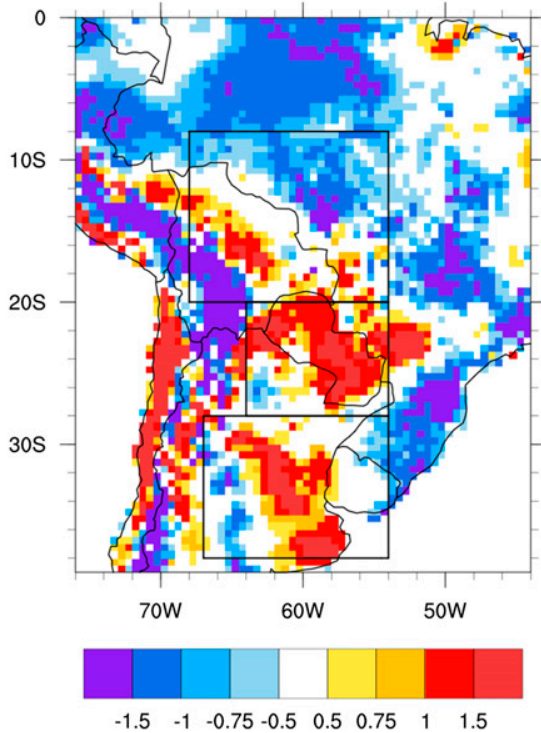

FIG. 2. Near-surface temperature according to (left) the CRU TS3.21 dataset, (center) the FD simulation, and (right) their difference averaged during (top) JJA and (bottom) OND.

example, previous studies report good skill of some parameterizations in some regions of South America, but a poor performance in other regions of the continent [see Solman and Pessacg (2012) for a comprehensive sensitivity study with MM5]. Despite the importance of reducing biases in the model, the present sensitivity study focuses on the differences between two model configurations (namely, with and without a groundwater scheme). In particular, no attempt to calibrate the model has been made. Some comments about the biases in the GW and FD simulations with respect to the reference datasets CRU TS3.21 and TRMM 3B43 are included at the end of section 3 .

\section{Results}

Two simulations have been performed for the entire period 2006-09, with and without the MMF groundwater scheme. The use of full multiyear simulations, as opposed to multiple simulations for just one season (as in Anyah et al. 2008), responds to the need for allowing the groundwater scheme to operate during the dry season 
TRMM-3B43 PCP(mm/day), JJA

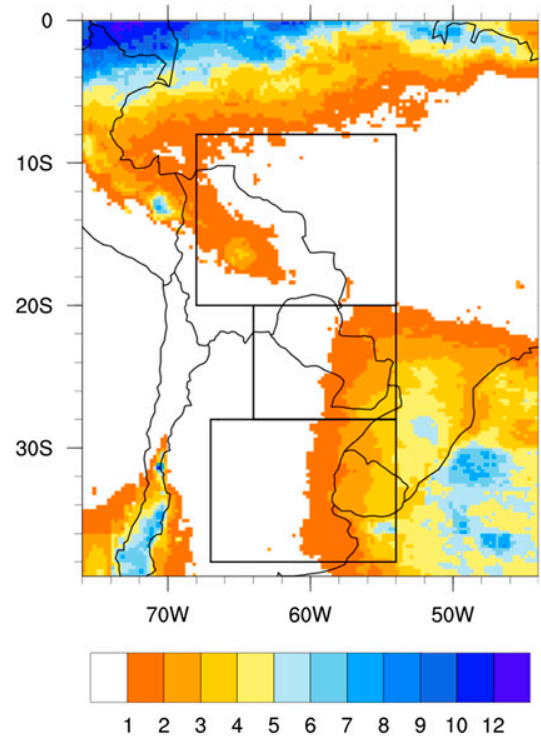

TRMM-3B43 PCP(mm/day), OND

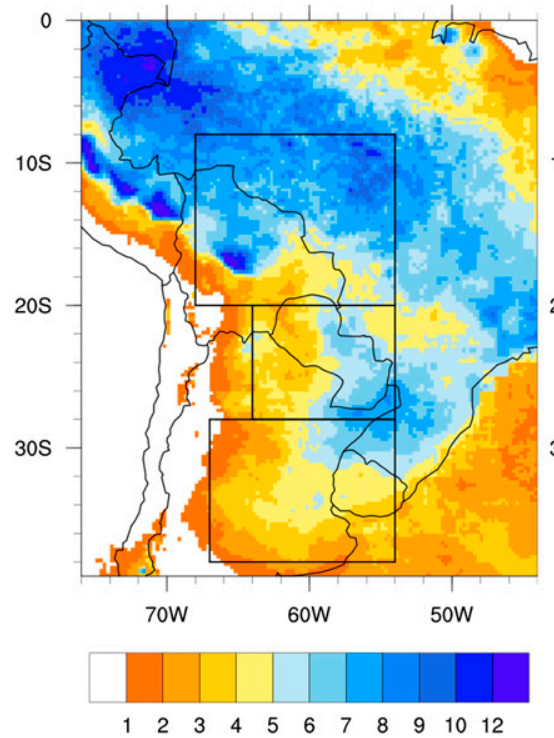

FD RAINRATE(mm/day), JJA

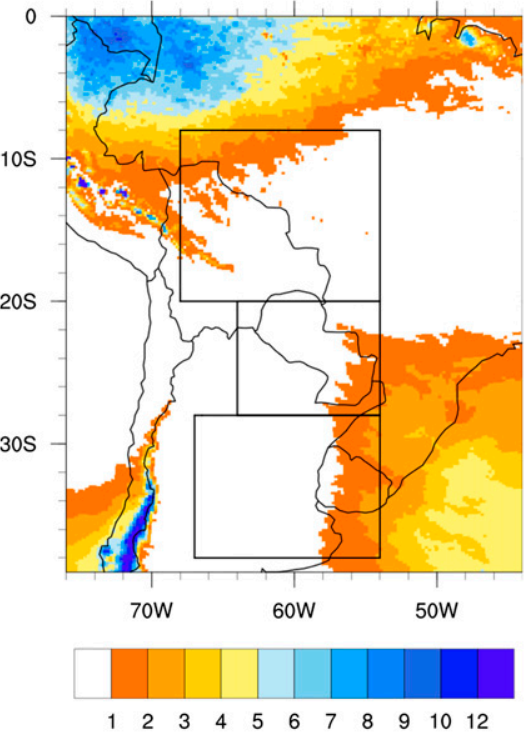

FD RAINRATE(mm/day), OND

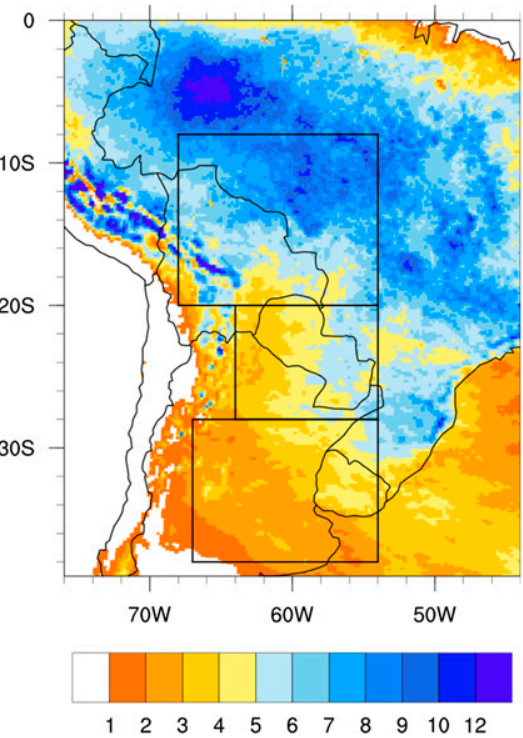

FD-TRMM-3B43 PCP(mm/day), JJA

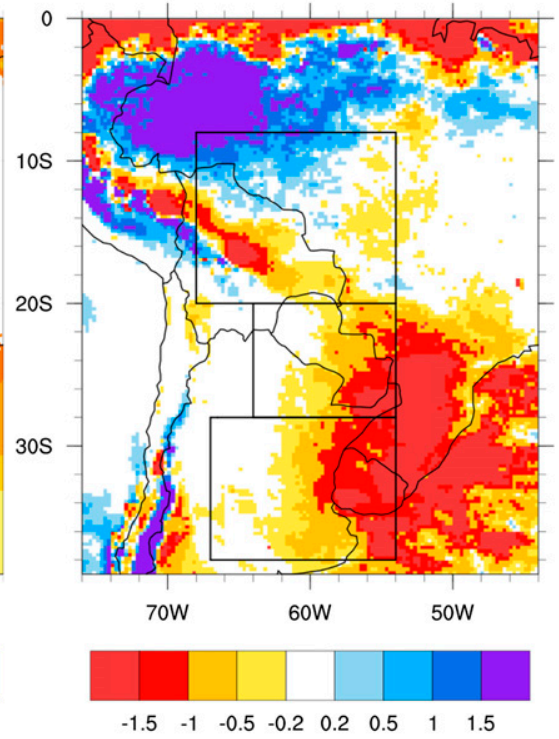

FD-TRMM PCP(mm/day), OND

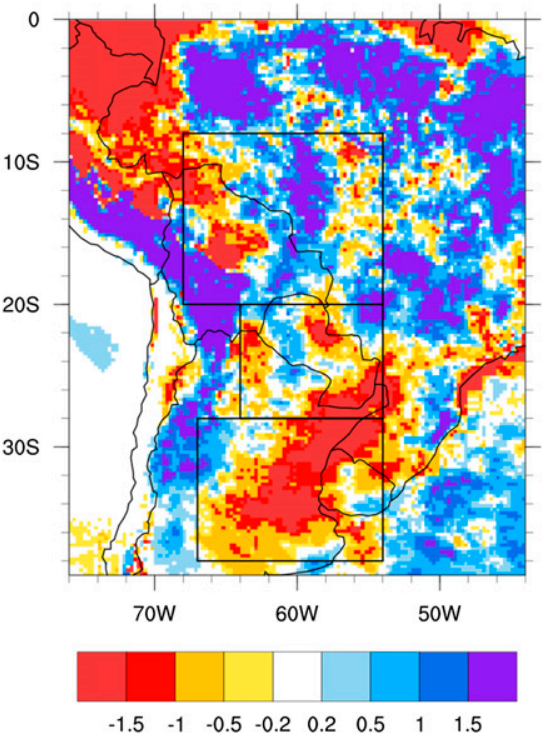

FIG. 3. Precipitation according to (left) the TRMM 3B43 dataset, (center) the FD simulation, and (right) their difference averaged during (top) JJA and (bottom) OND.

and assessing its accumulated impact during transition seasons. This strategy has been suggested but not explored in previous studies (e.g., Anyah et al. 2008). The analysis of the dry season itself also allows the identification of the effects of the groundwater scheme on soil moisture and evapotranspiration when the effects of precipitation on these variables are at a minimum.

\section{a. Recharge and water-table depth}

The MMF scheme introduces a dynamic water-table depth $Z_{\mathrm{WT}}$ and a vertical flux between the shallow aquifer and the unsaturated soil layers [recharge $(\mathrm{RECH})]$. Seasonal averages of both variables (which are exclusive of the GW simulation) are shown in Fig. 4. The water table can be within the resolved soil layers, and the RECH flux can be upward, from the aquifer to the soil layers above due to capillary forces, depending on the vertical gradient of moisture content. In contrast, in the FD simulation the flow of moisture in the bottom of the deepest soil layer is only downward and is solely determined by the action of gravity and the hydraulic conductivity of the soil. In the GW simulation, the 
GW RECH(mm/day), JJA

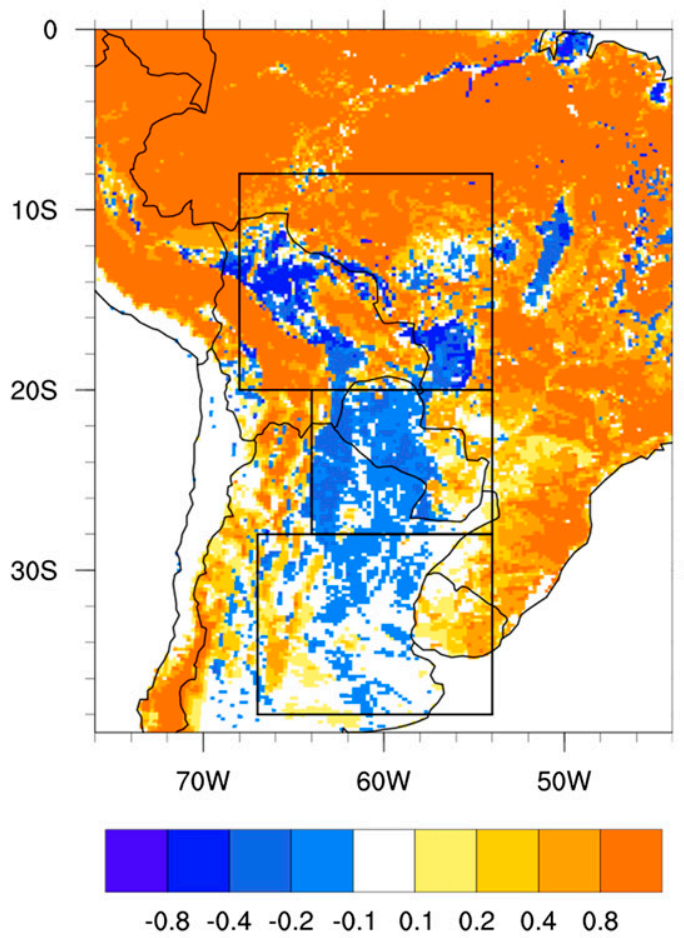

GW ZWT(m), JJA

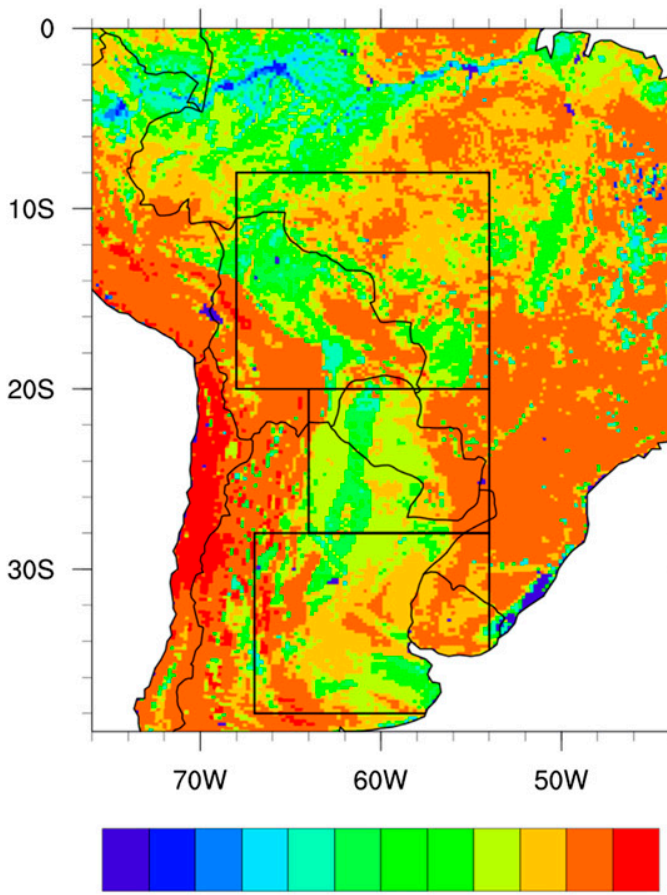

$\begin{array}{lllllllllll}0.5 & 1 & 1.5 & 2 & 2.5 & 3 & 3.5 & 4 & 5 & 10 & 40\end{array}$
GW RECH(mm/day), OND

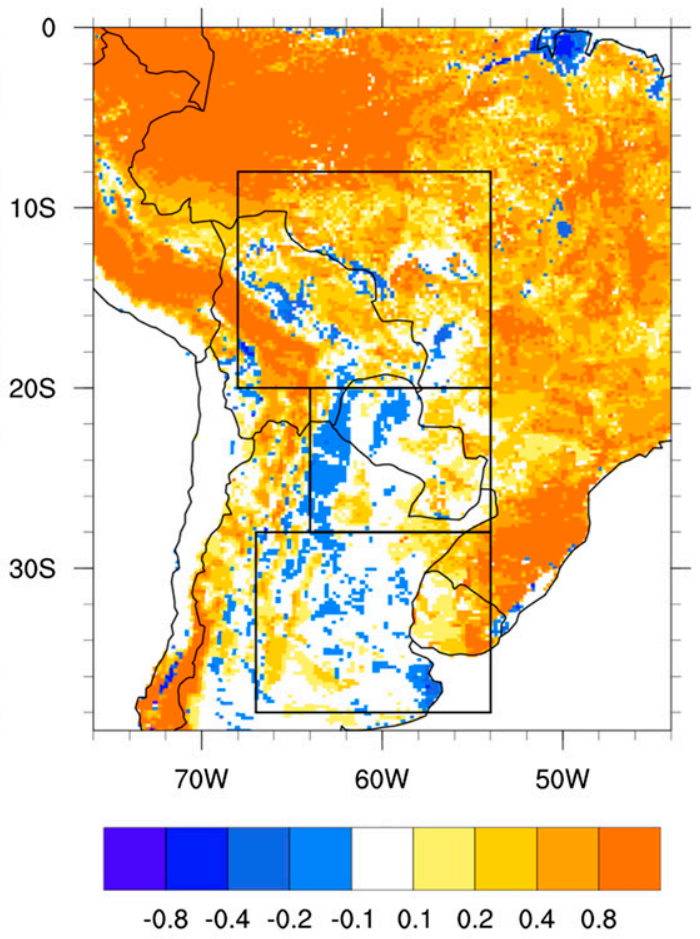

GW ZWT(m), OND

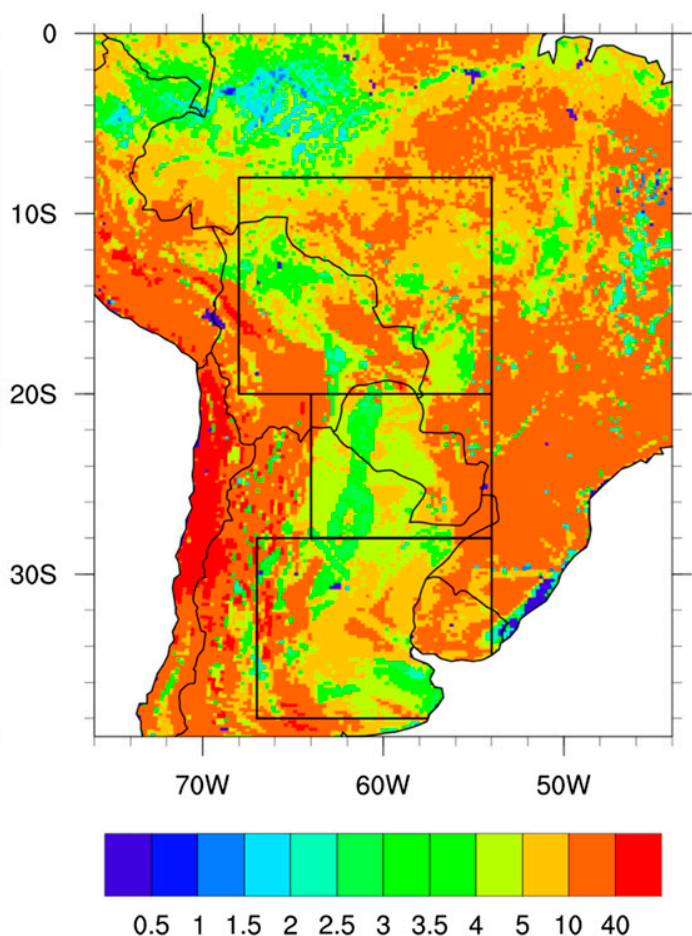

FIG. 4. (top) Average moisture flux between the shallow aquifer and the soil layers above (RECH) during (left) JJA and (right) OND. Negative values represent upward flux. (bottom) Average water-table depth (i.e., $Z_{\mathrm{WT}}$ ) during (left) JJA and (right) OND. 
interaction with the shallow aquifer makes the drainage of moisture from the soil layers above it to be slower compared with the FD simulation, where no aquifer is included. In those regions where the flow is from the aquifer to the soil layers above, the soil moisture in the unsaturated layers can increase in the GW simulation, while it may be decreasing in the FD simulation as a result of continuous draining [see, e.g., Miguez-Macho and Fan (2012) for a detailed analysis of these fluxes].

Over the La Plata basin, the vertical flux between the aquifer and the unsaturated layers is upward over some regions, due to capillary forces in the GW simulation [blue regions in Fig. 4 (top), most pronounced during the dry season]. Both the reduction of the drainage rate and the existence of an upward capillary flux increase soil moisture in the GW simulation with respect to the FD simulation. Upward capillary fluxes are larger during the dry season because of a decrease in the moisture content of the unsaturated soil layers (from evapotranspiration and runoff) above the shallow aquifer and the consequent increase in the moisture gradient. The largest effects take place in regions and seasons where the water table is more shallow and where the evapotranspiration is predominantly limited by the availability of water (as opposed to radiation), including parts of Bolivia, the Pantanal (both regions included in the box we are calling "southern Amazon"), and the central and southern La Plata basin during the dry season JJA (Fig. 4, bottom).

Kuppel et al. (2015) report water-table depths mostly in the range $1-3 \mathrm{~m}$ over the western Pampas $\left(36^{\circ}-34^{\circ} \mathrm{S}\right.$, $64^{\circ}-61^{\circ} \mathrm{W}$ ), where the current simulation shows values deeper than $5 \mathrm{~m}$. Observations compiled by Fan and Miguez-Macho (2010) show values smaller than $2.5 \mathrm{~m}$ for other regions in the La Plata basin. Their model results also suggest a water-table depth shallower than $2.5 \mathrm{~m}$ over northern Bolivia, the Pantanal region, and the La Plata basin (Fan and Miguez-Macho 2010). The closer the water table is to the land surface, the slower is the soil moisture drainage or the larger the upward capillary flux. On the contrary, the deeper the water table, the more the decoupling between the groundwater and soil moisture in the unsaturated zone. Because the vertical flux of moisture depends on the depth to the water table, our simulations may underestimate the effect of the groundwater over the La Plata basin by simulating a deeper water-table distribution compared with a more realistic distribution. The overestimation of the water-table depth (i.e., deeper than in reality) could be a result of the lack of calibration of Noah-MP and/or the groundwater parameters. While no attempt to calibrate Noah-MP to improve the estimates of ET has been made, the groundwater parameters were obtained from long-term conditions ( $\sim 30$ years $)$ of ET, precipitation, and runoff (Fan and Miguez-Macho 2010) that are not necessarily representative of WRF long-term means, which are not available for this study because of computational constraints.

\section{b. Dry season (JJA)}

As mentioned in the previous paragraph, as a consequence of the reduced drainage of soil moisture or the existence of an upward flux of moisture from the aquifer to the unsaturated soil layers above, the moisture in the top $2 \mathrm{~m}$ of the soil (root zone of the model) $\mathrm{SM}_{2 \mathrm{~m}}$ is larger in the GW simulation compared to the FD simulation (Fig. 5). The largest increase is observed over those regions where the water table is shallower (see Fig. 4). The increase can be larger than $20 \%$ of the absolute value in the FD simulation over parts of the La Plata basin. As a direct result of more moisture in the root zone, there is an increase in ET in the GW simulation (Fig. 5). This increase is larger over the central La Plata basin, the Pantanal region, and northern Bolivia, where ET is predominantly limited by water availability. On the contrary, no evident increase in ET is observed over northwestern Brazil (western Amazon), where ET is limited by radiation (e.g., Fisher et al. 2009). Because of the small values of the simulated ET during the dry season over these regions, the relative increase in the GW simulation can be as large as $50 \%$ of the values in the FD simulation. However, absolute values of more than $0.5 \mathrm{~mm} \mathrm{day}^{-1}$ extra ET are also observed over the central La Plata basin in the GW simulation. This difference between the GW and FD simulations is statistically significant.

The increase in ET is associated with a decrease in sensible heat flux (not shown), which in turn decreases the near-surface temperature (e.g., the 2-m temperature $T_{2 \mathrm{~m}} ;$ Fig. 5). The decrease in $T_{2 \mathrm{~m}}$ can be larger than $1^{\circ} \mathrm{C}$ over those regions where ET increases the most (central La Plata, Pantanal, and northern Bolivia). The increase in ET also induces an increase in near-surface specific humidity (e.g., the specific humidity at $2 \mathrm{~m}$ AGL $Q_{2 \mathrm{~m}}$; Fig. 5). The near-surface winds seem to play a role in the distribution of the excess of specific humidity, producing an accumulation of moisture over the west of the central La Plata and some transport to the northwest of the southern La Plata region. Note that the increase in specific humidity over the central La Plata is a substantial fraction of its total value in the FD simulation. During the dry season, this extra moisture is not consumed by precipitation because of the seasonal minimum in local rainfall.

The dry season JJA corresponds to the austral winter, with relatively high values of the LCL and low values of downward shortwave radiation $\left(\mathrm{SW}_{\mathrm{DOWN}}\right)$, convective 

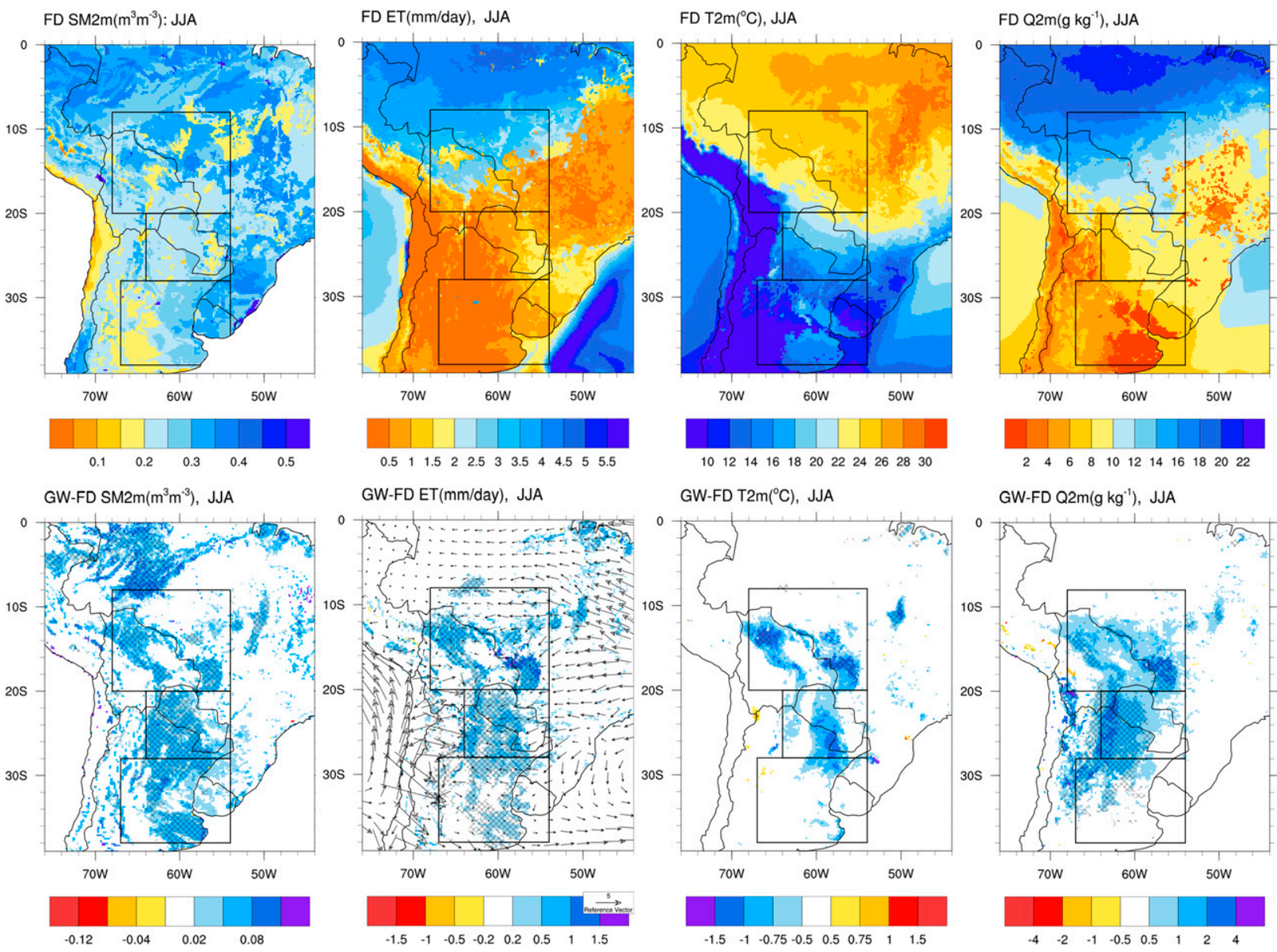

FIG. 5. (top) Average $\mathrm{SM}_{2 \mathrm{~m}}, \mathrm{ET}, T_{2 \mathrm{~m}}$, and $Q_{2 \mathrm{~m}}$ from the FD simulation for JJA. (bottom) Average differences in $\mathrm{SM}_{2 \mathrm{~m}}, \mathrm{ET}, T_{2 \mathrm{~m}}$, and $Q_{2 \mathrm{~m}}$ between the GW and the FD simulations for JJA. The total 10-m winds from the GW simulation are drawn on top of the ET differences. Hatching indicates differences statistically significant at the 0.1 level according to a two-tailed Student's $t$ test.

available potential energy (e.g., MCAPE), and precipitation (RAINRATE) over the La Plata basin (Fig. 6). The decrease in near-surface temperature and the increase in near-surface humidity lead to a decrease in the LCL and $\mathrm{SW}_{\text {DOWN }}$ (from increased cloudiness) in the GW simulation. However, both changes are a small fraction of the absolute values of LCL and $\mathrm{SW}_{\text {DOWN }}$ in the FD simulation. Over the southern Amazon, there is also a visible increase in MCAPE, with values larger than $10 \%$ relative to the FD simulation. Some increase in MCAPE is also observed over the southern La Plata basin. There is an increase in precipitation in the GW simulation over southeastern South America (including Uruguay and southern Brazil), which seems to be collocated with the dry bias in the FD simulation (see Fig. 3), downstream of the regions in the southern Amazon and the central La Plata where an increase in ET and near-surface moisture is observed (see ET and $Q_{2 \mathrm{~m}}$ in Fig. 5 and the 850-hPa winds in Fig. 6). The magnitude of the increase in precipitation is small in absolute value, but larger than $10 \%$ relative to the FD simulation values (cf. the absolute precipitation FD and the difference GW - FD in Fig. 6).

Note that the differences in $\mathrm{SM}_{2 \mathrm{~m}}$, ET, and $Q_{2 \mathrm{~m}}$ are statistically significant (Fig. 5) over larger areas than in the case of other variables. The differences in MCAPE and precipitation (Fig. 6), although systematic and physically consistent with the changes in ET, are not statistically significant.

\section{c. OND season}

We describe now the observed changes in hydroclimatological conditions during the early rainy season (OND), when the largest difference in precipitation between the FD and GW simulations was observed. Figure 7 shows the mean absolute values of $\mathrm{SM}_{2 \mathrm{~m}}$, ET, $T_{2 \mathrm{~m}}$, and $Q_{2 \mathrm{~m}}$ in the FD simulation (Fig. 7, top) and the corresponding differences with the $\mathrm{GW}$ simulations (GW - FD; Fig. 7, bottom). The differences in $\mathrm{SM}_{2 \mathrm{~m}}$ are larger than during the dry season because of the 


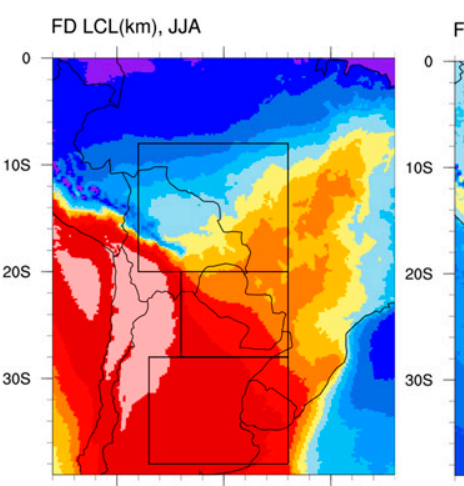

70W $\quad 60 \mathrm{~W} \quad 50 \mathrm{~W}$

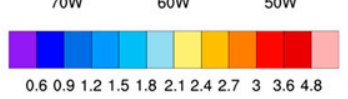

GW-FD LCL(m), JJA

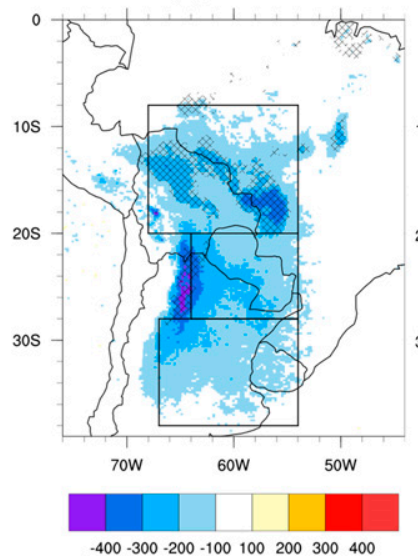

FD SWDOWN(W m $\left.{ }^{-2}\right)$, JJA

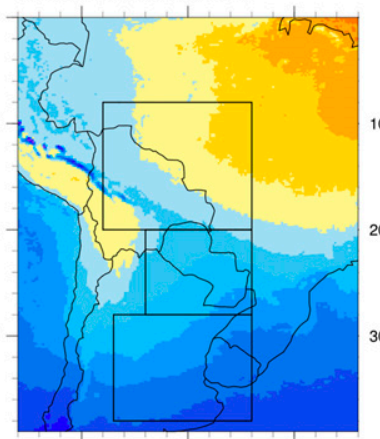

70w

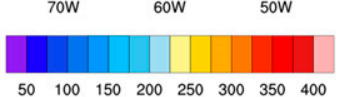

GW-FD SWDOWN $\left(W^{-2}\right)$, JJA

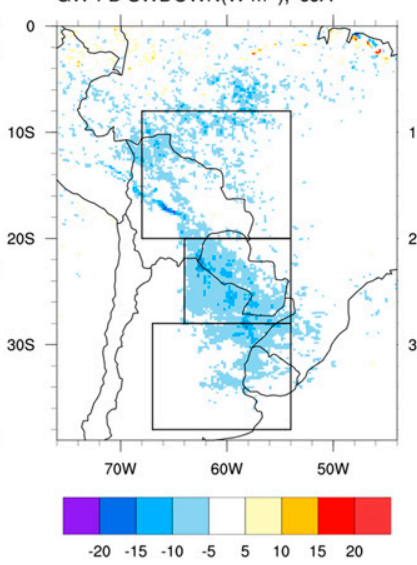

FD MCAPE $\left(\mathrm{J} \mathrm{kg}^{-1}\right)$, JJA

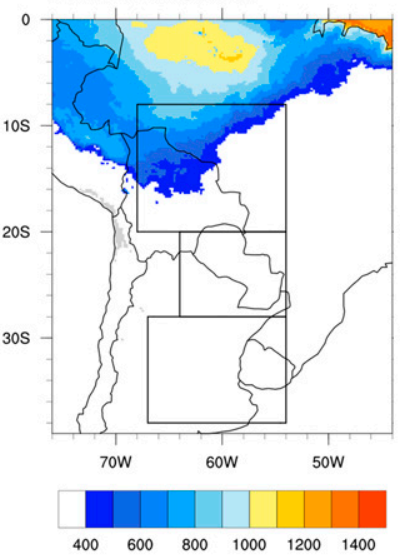

GW-FD MCAPE $\left(\mathrm{J} \mathrm{kg}^{-1}\right)$, JJA
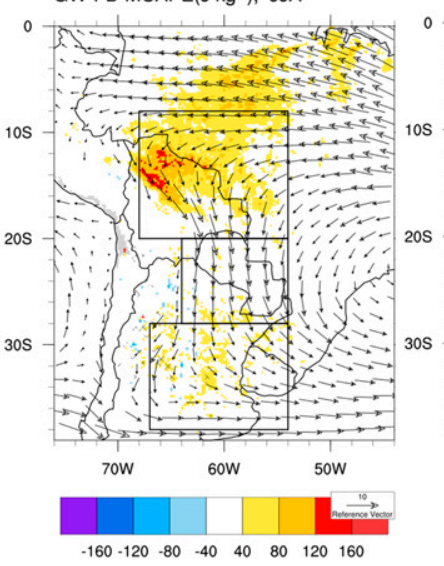

FD RAINRATE(mm/day), JJA

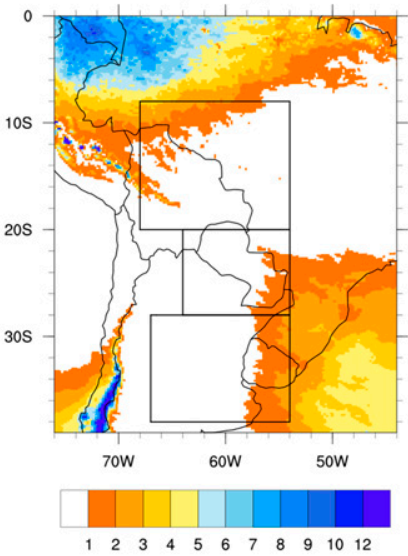

GW-FD RAINRATE(mm/day), JJA

FIG. 6. (top) Average LCL, SW DOWN, MCAPE, and RAINRATE from the FD simulation for JJA. (bottom) Average differences in LCL, $\mathrm{SW}_{\text {DOWN }}$, MCAPE, and RAINRATE between the GW and the FD simulations for JJA. The total 850-hPa winds from the GW simulation are drawn on top of the MCAPE differences. Hatching indicates differences statistically significant at the 0.1 level according to a two-tailed Student's $t$ test.

accumulated effect of weaker drainage/upward fluxes during the dry season JJA, plus slower drainage of soil moisture from precipitation in the GW simulation compared to the FD simulation during the OND season. The location of the largest differences in $\mathrm{SM}_{2 \mathrm{~m}}$ is still determined by the water-table depth (see Fig. 4). With the increase in $\mathrm{SM}_{2 \mathrm{~m}}$ in the GW simulation relative to the FD simulation, there is an increase in ET. The difference in ET during OND is also larger than the difference in JJA, because of the larger difference in $\mathrm{SM}_{2 \mathrm{~m}}$ during OND. There is no increase in ET over the radiation-limited northwest of the domain (western Amazon basin). The increase in ET in the GW simulation is a significant fraction of the ET from the FD simulation. For example, the extra ET in the GW simulation can be in the range $0.5-1.0 \mathrm{~mm}^{-1 a y^{-1}}$ over parts of the southern La Plata basin, where the total ET in the FD simulation is in the range $2.5-3.0 \mathrm{~mm} \mathrm{day}^{-1}$. As it was observed during the dry season, with the increase in
ET there is a decrease in $T_{2 \mathrm{~m}}$, mostly in the range of $0.5^{\circ}-1.0^{\circ} \mathrm{C}$. The increase in $Q_{2 \mathrm{~m}}$ associated with the extra ET is much smaller compared with the values observed during the dry season (note the difference in scales in Figs. 5 and 7 for $Q_{2 \mathrm{~m}}$ ). This difference could be due to the higher consumption of moisture by the extra precipitation in the GW simulation during the OND season (see below). The increase in $Q_{2 \mathrm{~m}}$ during OND, although small, contributes to an increase in the moist static energy (see below).

The increase in moisture and decrease in temperature in the GW simulation led to a decrease in the LCL, when compared to the FD simulation (Fig. 8). This decrease can be on the order of $10 \%$ and larger over parts of the La Plata basin. The changes in the downward shortwave radiation associated with a decrease in LCL (more clouds) are small and are mostly confined to the eastern slopes of the Andes. This suggests that the increase in cloudiness from the lowering of the LCL does not 

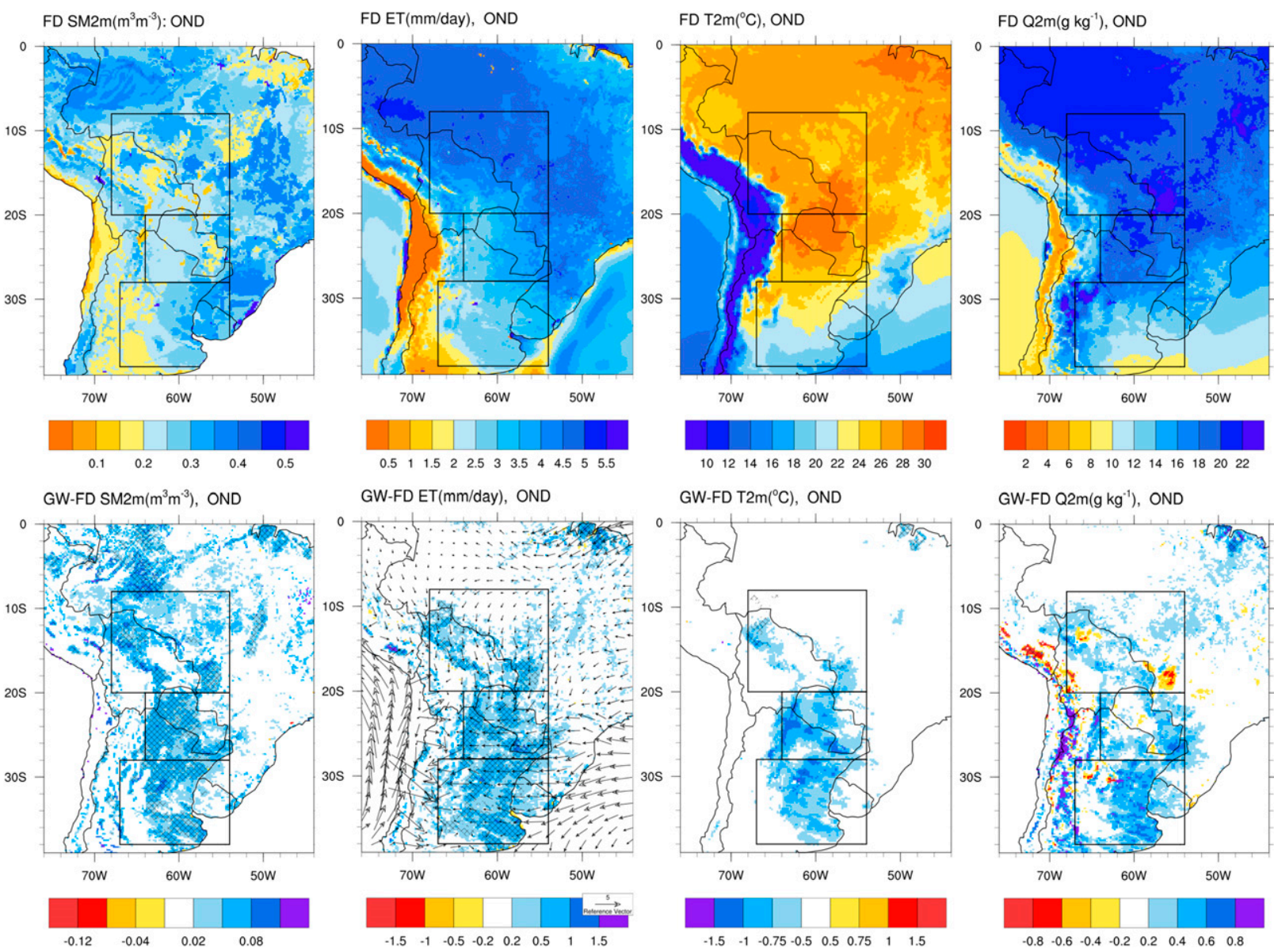

FIG. 7. As in Fig. 5, but for OND. Note the difference in scale in the difference in GW - FD $Q_{2 \mathrm{~m}}$. Hatching indicates differences statistically significant at the 0.1 level according to a two-tailed Student's $t$ test.

contribute substantially to a decrease in the incident solar radiation upon the surface. Such a decrease could potentially decrease ET, but the small magnitudes of the differences in $\mathrm{SW}_{\text {DOWN }}$ between both simulations suggest that this is not happening for the current decrease in LCL. On the other hand, the increase in ET and the associated decrease in sensible heat flux (see decrease in $T_{2 \mathrm{~m}}$ in Fig. 7) led to a decrease in the planetary boundary layer height (PBLH). This decrease is also larger than $10 \%$ of the PBLH in the FD simulation over the La Plata basin. Thus, we have two changes contributing in opposite ways to potential convection and precipitation over the region: the decrease in the LCL (and a corresponding decrease in the level of free convection) and the decrease in the boundary layer height (reducing the chances of near-surface thermals to reach higher levels in the atmosphere). Note that the decrease in LCL is larger than the decrease in PBLH.

Vertical profiles of relative humidity and moist static energy averaged over the boxes representing the central and southern parts of the La Plata basin are shown in Fig. 9. The increase in moisture and the decrease in temperature (see, e.g., $Q_{2 \mathrm{~m}}$ and $T_{2 \mathrm{~m}}$ in Fig. 7) lead to an increase in RH. However, this increase is small (maximum difference is on the order of $3 \%-5 \%)$. In both regions (central and southern La Plata), the RH profiles in both simulations (GW and FD) are virtually identical above the 800 -hPa level. Similarly, despite the decrease in temperature, there is a net small increase in the MSE in the lower levels of the atmosphere over both regions. This is due to the large value of the latent heat of vaporization: a small amount of extra moisture contains a large amount of moist static energy, compensating for the decrease from the lower temperature. Over both regions, the increase of MSE in the lower levels is associated with an increase in CAPE, although this increase is smaller over the southern La Plata (see below). The vertical profiles in Fig. 9 illustrate how the overall largest effects of the groundwater scheme are confined to the lowest layers of the atmosphere. 
FD SWDOWN $\left(\mathrm{W} \mathrm{m}^{-2}\right)$, OND

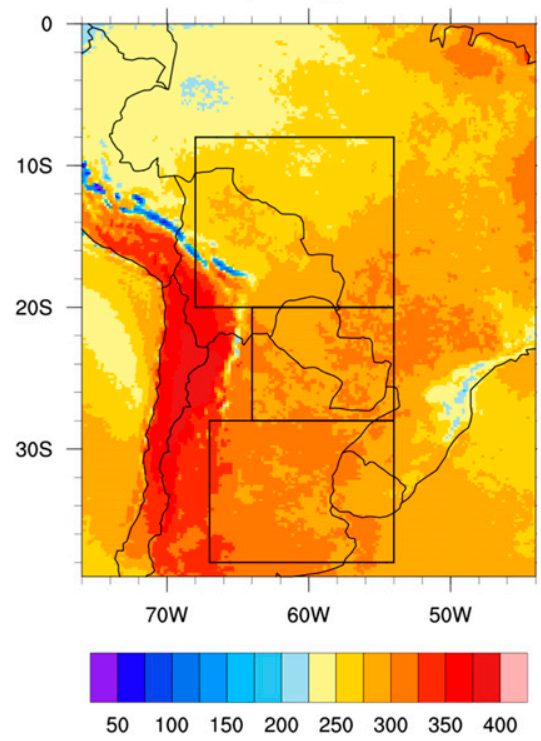

GW-FD SWDOWN $\left(\mathrm{W} \mathrm{m}^{-2}\right)$, OND

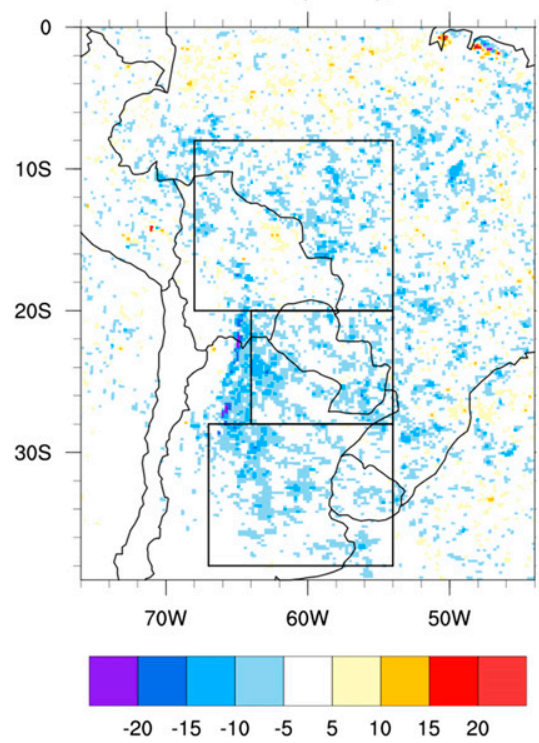

FD LCL(km), OND

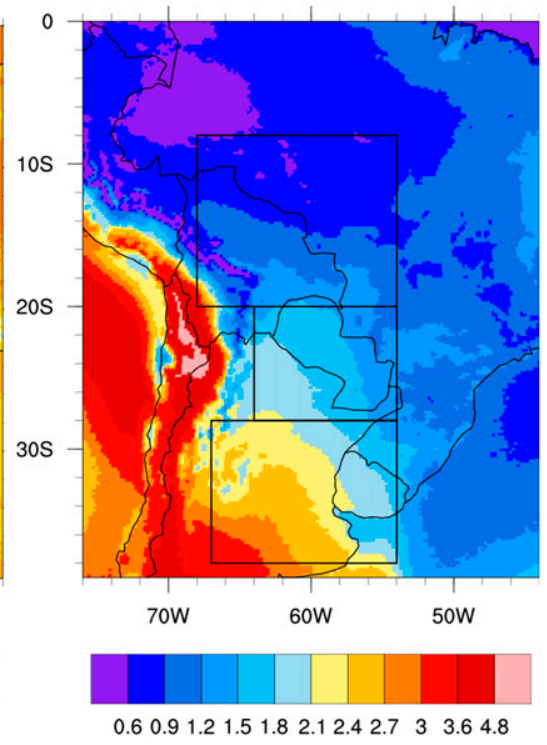

GW-FD LCL(m), OND

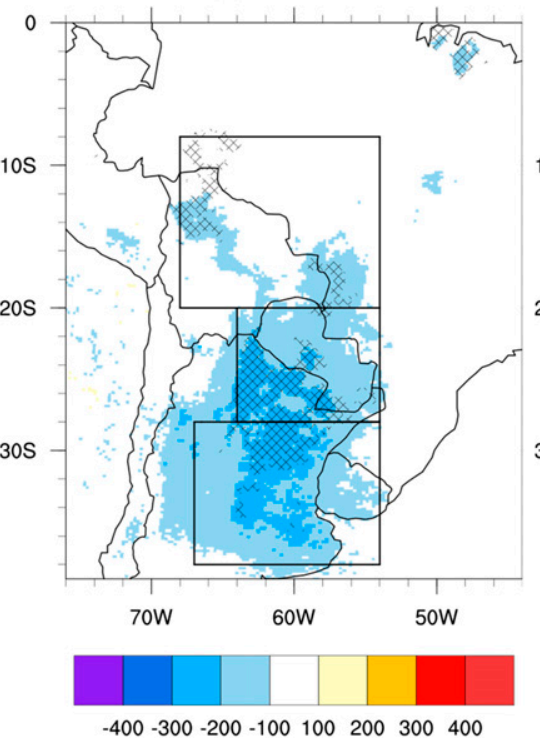

FD PBLH $(m)$, OND

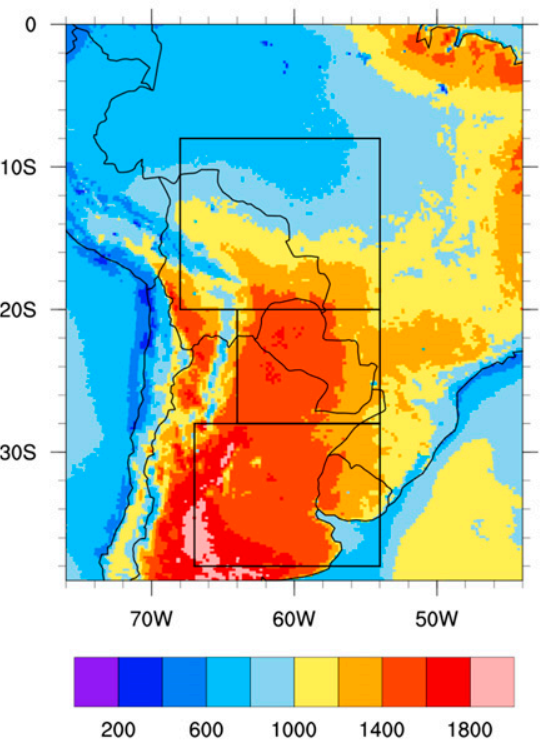

GW-FD PBLH(m), OND

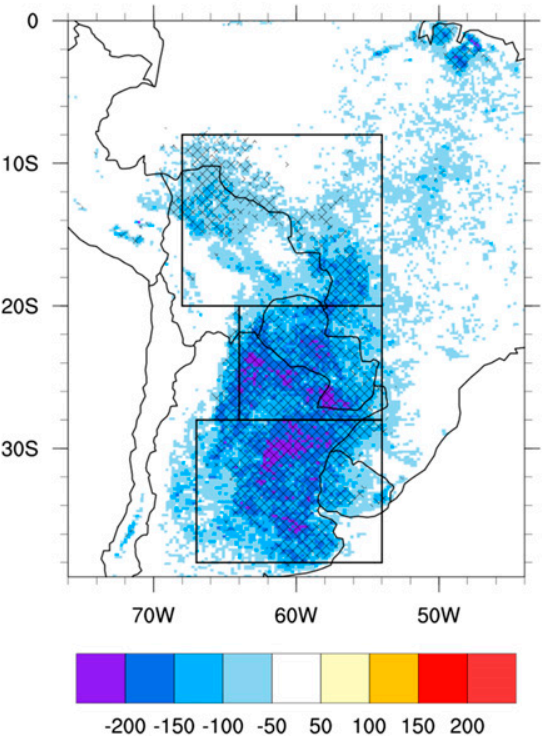

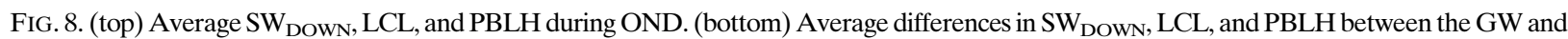
FD simulations during OND. Hatching indicates differences statistically significant at the 0.1 level according to a two-tailed Student's $t$ test.

Despite the increase in relative humidity and moist static energy, and the decrease in the LCL, the decrease in sensible heat flux and temperature in the lowest levels could have a negative impact on the potential development of convection over the region. The role of the two competing mechanisms in the development of convection in the present simulations (increase in moisture and reduction of sensible heat flux) is different throughout the La Plata basin, as can be seen in Fig. 10. In the GW simulation, MCIN increases over parts of the southern La Plata basin, due to the reduction in the low-level temperatures, from the increase in ET. Thus, the decrease in temperature overcompensates the potential positive effect of a lower LCL for the generation of moist convection and precipitation over these regions. Note that the increase in MCIN can be as large as $10 \%$ of the value from the FD simulation. Over the central La Plata basin, such large increases in MCIN are not observed.

At the same time, there is a general increase in MCAPE (Fig. 10), associated with the increase in moist static energy in the lowest levels (Fig. 9). The increase is more pronounced in parts of the central La Plata basin, 

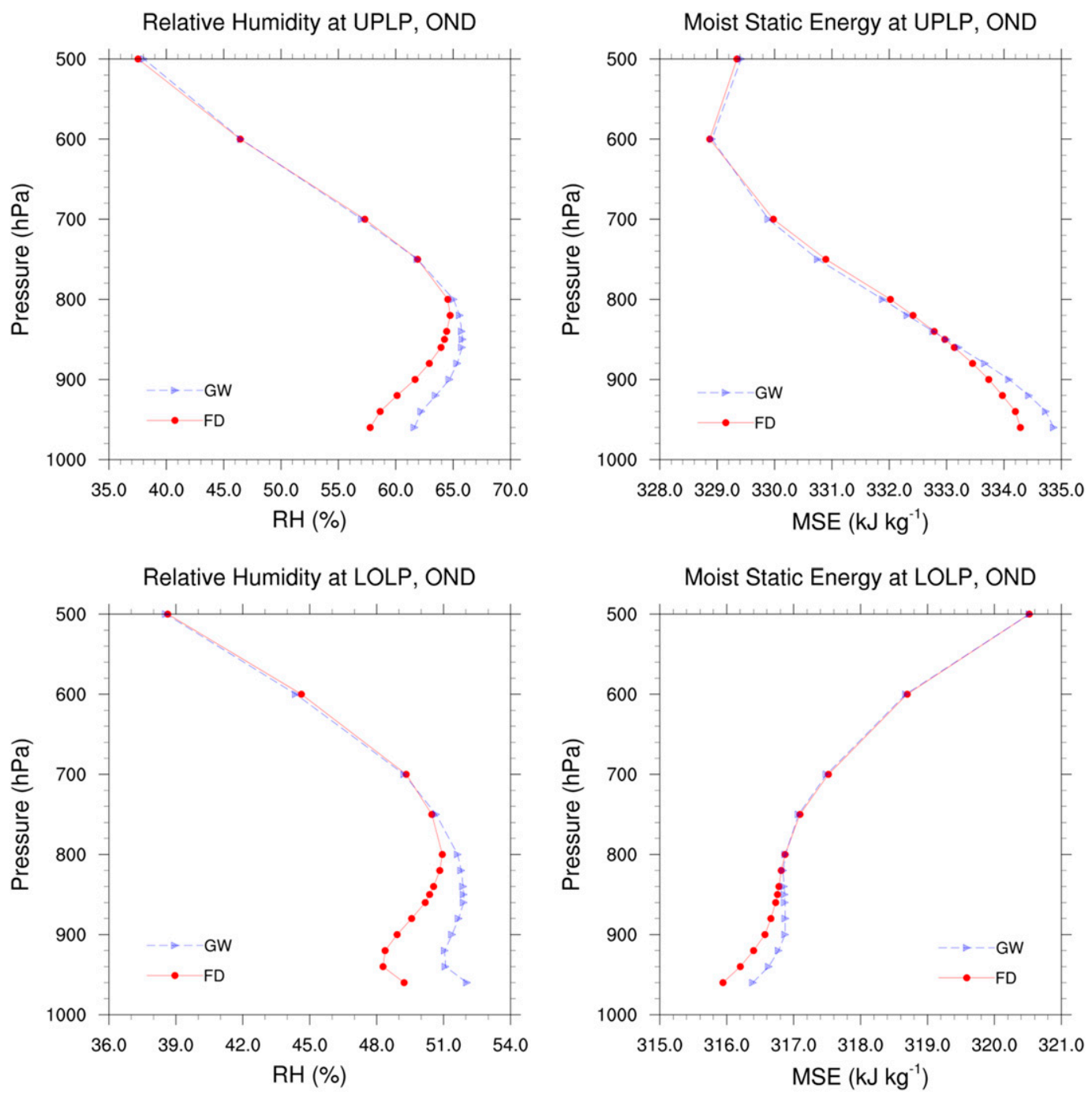

FIG. 9. Vertical profiles of (left) RH and (right) MSE averaged over (top) UPLP and (bottom) LOLP during OND.

although a smaller increase is also seen over the southern La Plata basin (in the range $10-40 \mathrm{~J} \mathrm{~kg}^{-1}$, not shown). As a result of the distribution of the convective inhibition and convective available potential energy (as suggested by the MCIN and MCAPE diagnostics), the cumulus scheme tends to produce more convective precipitation $\left(\mathrm{RAIN}_{C}\right)$ downstream of the central La Plata basin, but less over the southern extreme of the southern La Plata. However, over this region, there is a significant contribution to precipitation from the microphysics scheme [nonconvective precipitation $\left(\right.$ RAIN $\left._{\mathrm{NC}}\right)$ ], due to the extra humidity in the GW simulation that is not "used" by the cumulus scheme due to the increased convective inhibition. Note that over the southern La Plata, the contribution of convective (from RAIN $_{C}$ ) and large scale (from RAIN ${ }_{N C}$ ) to total precipitation (Fig. 10, top) is of the same order.
The differences in $\mathrm{SM}_{2 \mathrm{~m}}$, ET (Fig. 7), and PBLH (Fig. 8) when the groundwater scheme is included are statistically significant. The changes in other variables (Figs. 7, 8, and 10) are physically consistent with the changes in ET, but not statistically significant.

As a result of the availability of moisture and/or the increase of convective instability, the GW simulation yields an increase in total precipitation (i.e., convective plus nonconvective or large-scale precipitation) over different parts of the La Plata basin (Fig. 11). (The total precipitation from the FD simulation is the same as in Fig. 3, reproduced here for easier comparison with the changes due to the GW scheme.) Figure 11 (center) shows a spatially uniform increase (i.e., in sign, not in magnitude) in precipitation over the southern La Plata basin, with a noisier pattern in the rest of the domain. Figure 11 (right) shows the fractional differences 

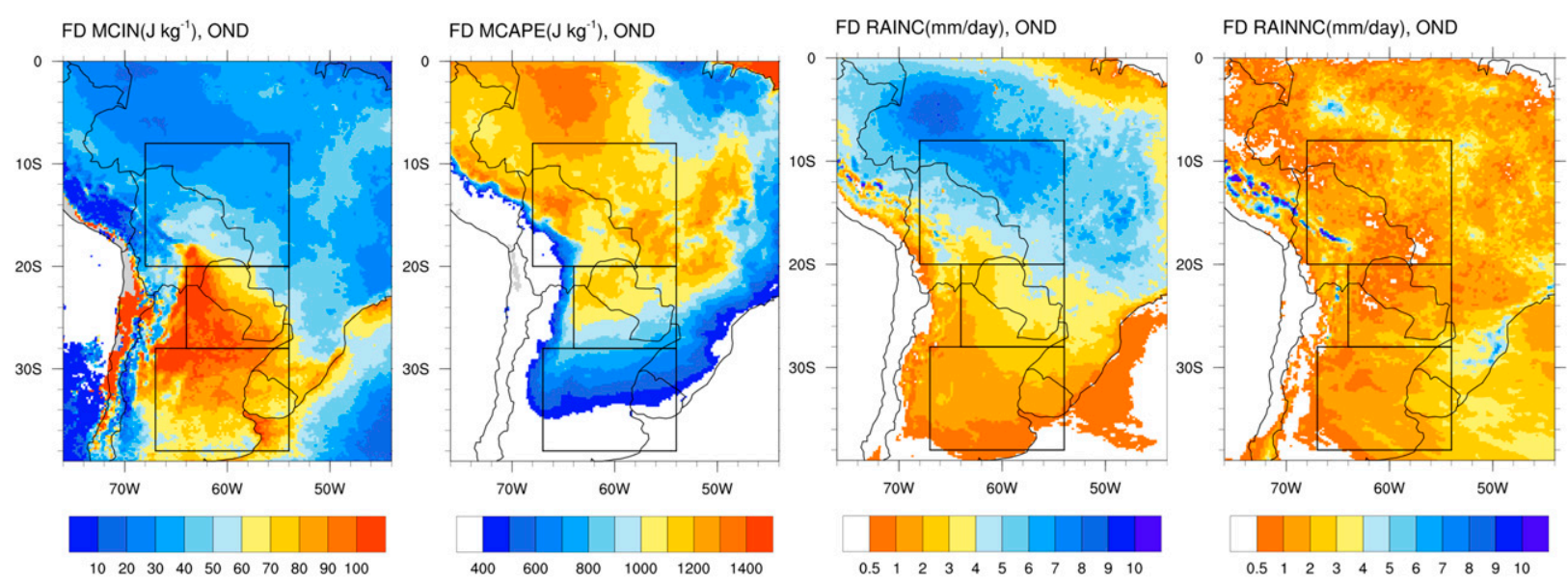

$102030 \quad 4050 \quad 6070 \quad 8090 \quad 100$

GW-FD MCAPE $\left(\mathrm{J} \mathrm{kg}^{-1}\right)$, OND
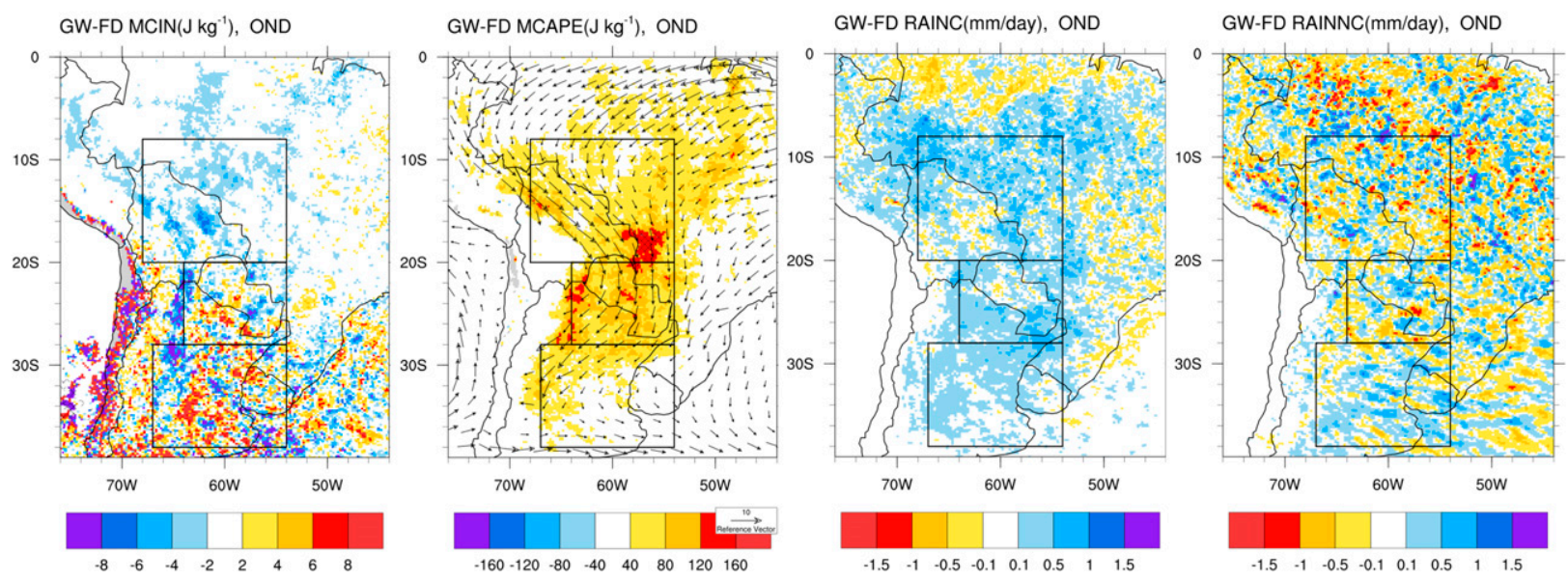

FIG. 10. (top) Average MCIN, MCAPE, RAIN ${ }_{C}$, and RAIN ${ }_{N C}$ during OND. (bottom) Average differences in MCIN, MCAPE, RAIN $C$, and RAIN $_{\mathrm{NC}}$ between the GW and FD simulations during OND. Hatching indicates differences statistically significant at the 0.1 level according to a two-tailed Student's $t$ test.

between the simulations, estimated as $(\mathrm{GW}-\mathrm{FD}) / \mathrm{FD}$ for each grid cell. The largest fractional differences are found over the southern La Plata basin and parts of the central La Plata basin. The local relative differences over the La Plata basin can reach values as large as $30 \%$, although the absolute magnitudes are rather small (mostly in the $0.1-0.5 \mathrm{~mm} \mathrm{day}^{-1}$ range). The map of fractional differences also shows the relatively weaker and spatially heterogeneous changes in other parts of the domain, like the southern Amazon region.

A more general view of the regional changes in precipitation $P$ and ET due to the groundwater scheme can be derived from the regional averages for the southern La Plata box, as shown in Fig. 12. Figures 12a and 12b show that the regional averages of ET and $P$, respectively, are very similar between the GW and FD simulations. These monthly averages also show the variations from year to year during the 4 years of simulation, which includes a period of drought over the southern La Plata during 2008/09 (Chen et al. 2010;
Müller et al. 2014). The reduction in precipitation in both simulations is clear between November 2007 and October 2009. Despite the similarities in the values of ET and $P$, and their year to year variations, the GW simulation invariably produces more ET and precipitation in the OND months during the 4 years of simulation.

The absolute differences between both simulations (Fig. 12c) show that the extra precipitation in the GW simulation tends to be less than the extra ET (except in November 2006 and October 2007). However, the extra precipitation tends to be a relatively large fraction of the extra ET. For example, during December 2006, the extra ET from the GW simulation is nearly $0.32 \mathrm{~mm}_{\text {day }}{ }^{-1}$, while the extra $P$ is $0.22 \mathrm{~mm}_{\text {day }}{ }^{-1}$; thus, the extra $P$ is nearly $69 \%$ of the extra ET during this month. In general, the observed ratio of extra $P$ to extra ET during the OND months is in the range $\sim 30 \%-120 \%$. The estimated recycling ratio for the region is in the range $23 \%-42 \%$ (Dirmeyer et al. 2009a; Martinez and Dominguez 2014). 
FD RAINRATE(mm/day), OND

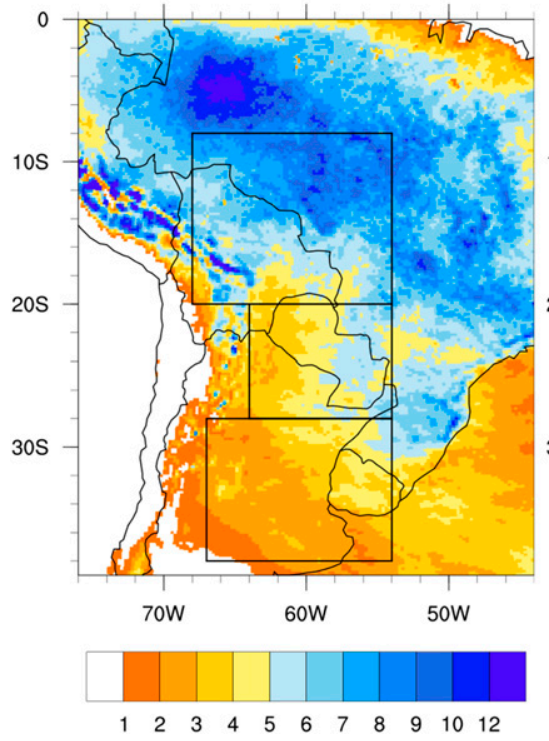

GW-FD RAINRATE(mm/day), OND

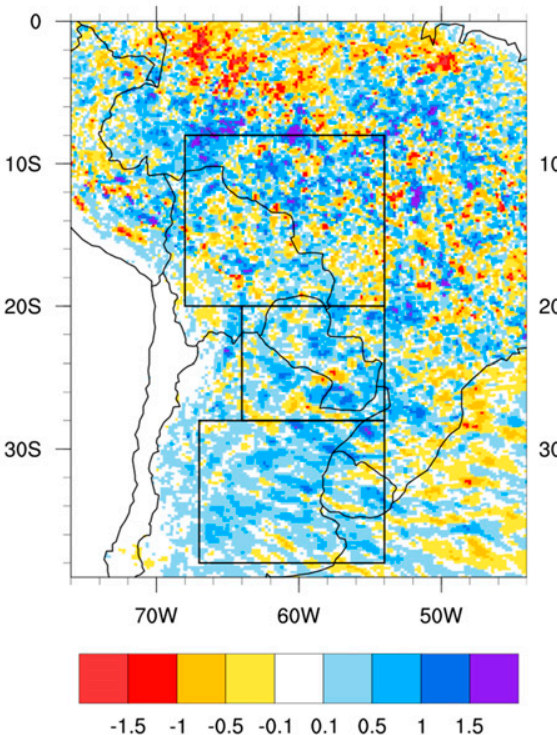

(GW-FD)/FD RAINRATE(-), OND

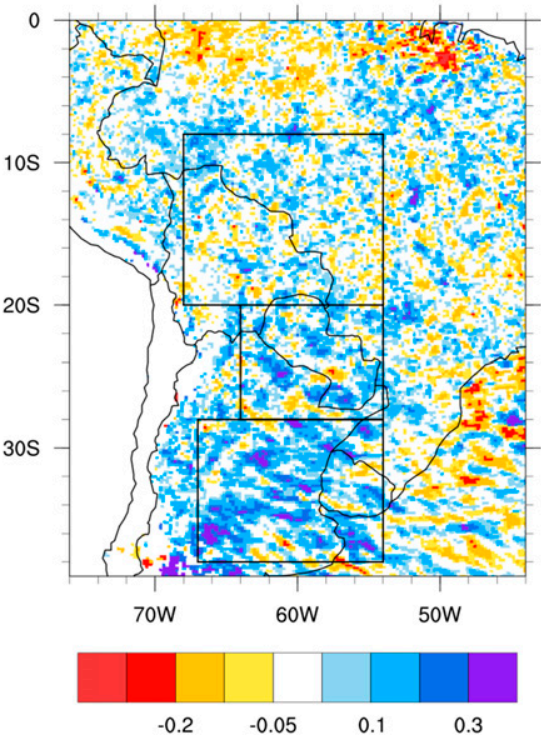

FIG. 11. (left) Total precipitation $\left(\mathrm{RAIN}_{C}+\mathrm{RAIN}_{\mathrm{NC}}\right.$ ) from the FD simulation. (center) Difference in total precipitation between GW and FD simulations; these differences are not statistically significant at the 0.1 level according to a two-tailed Student's $t$ test (except for a few isolated points). (right) Fractional difference in total precipitation between GW and FD simulations.

Thus, the extra precipitation in the GW simulation seems to be coming not only from direct recycling of the extra ET, but from the effects of ET on the stability of the local and upstream atmosphere, likely enhancing the indirect local production of precipitation (from the increase in local instability) and the transport from upstream regions (e.g., the central La Plata). This is consistent with the observed increase in moisture content, relative humidity, and convective available potential energy over the region (Figs. 7, 9, and 10). These mechanisms have been found to operate simultaneously in other regions, as described and discussed in previous studies (e.g., Schär et al. 1999).

The regional average of the increase in ET and precipitation in the GW simulation relative to the FD simulation values is shown in Fig. 12d. The overall fractional increase is in the range $2 \%-23 \%$. The mean relative increase in $\mathrm{ET}$ is $13 \%$, while the mean increase in precipitation is $10 \%$. Note that the local increase in ET (both absolute and relative) could actually be larger if computed only over the region where the largest increase in $\mathrm{SM}_{2 \mathrm{~m}}$ is observed, instead of the larger box representing the southern La Plata (see Fig. 7). In general, the groundwater scheme induces an increase in $P$ and ET over the La Plata basin all year round, with the largest increase around the OND season (see supplemental material).

Finally, we compare the mean temperature and precipitation from both the GW and FD simulations with the estimates based on CRU and TRMM products
(Fig. 13). Instead of using CRU temperature products directly, we use the adjusted temperature dataset developed by Wang and Zeng (2013), which is based on different reanalyses products, constrained by information of the hourly evolution of the temperature field as represented by MERRA, and the monthly field as estimated by a CRU temperature product. Here we show the comparison of WRF estimates of 2-m temperature to the adjusted ERA-Interim fields from Wang and Zeng (2013; available at http://rda.ucar.edu/ datasets/ds193.0/). The ERA-Interim adjusted product was chosen because it shows the smallest deviations from the CRU products over South America (Wang and Zeng 2013). To obtain estimates for 0000 UTC, we averaged the 0030 and 2330 UTC estimates from the previous day. A similar procedure was performed to obtain estimates at 0600, 1200, and 1800 UTC. Finally, these estimates were averaged to obtain a daily average that we can unambiguously compare to our WRF averages.

The general biases of WRF in temperature and precipitation (Fig. 13) are larger than the differences between the GW and the FD simulations (Figs. 5, 6, 7, and 11 ), which is evident in the common patterns for the different simulations in Fig. 13. The differences in temperature tend to be smaller over the La Plata basin, where Fig. 13 suggests a decrease in the warm bias. However, there is some extra cooling in the southern Amazon, in particular over the northeast corner of the box. Table 2 shows that the biases over the La Plata basin decrease in magnitude (with some extra cooling 
(a) Evapotranspiration

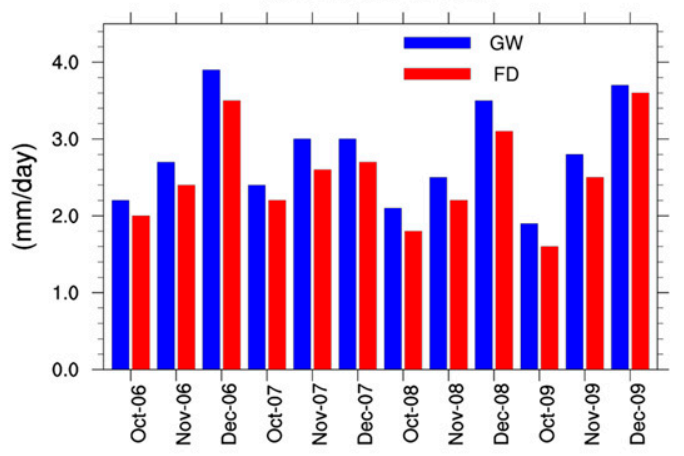

(c) GW-FD

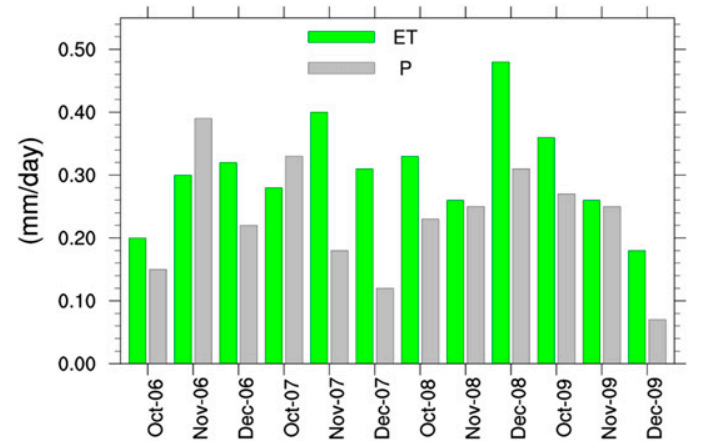

(b) Precipitation

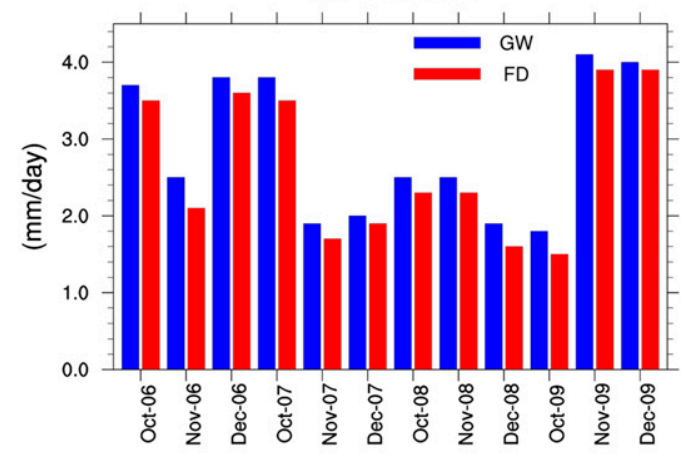

(d) $100 \% \times(G W-F D) / F D$

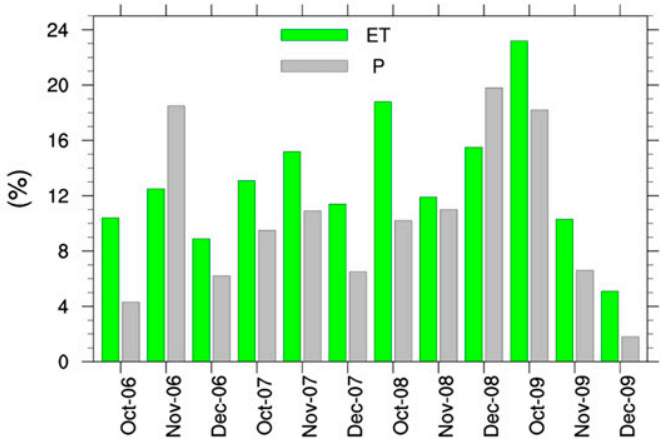

FIG. 12. (a) Average ET over the LOLP for each month of OND during the 4 years of simulation. (b) As in (a), but for average precipitation. (c) Absolute differences GW - FD in ET (green) and precipitation (gray). (d) Differences GW - FD in ET (green) and precipitation (gray) relative to FD averages (\%).

over the southern La Plata) while there is an increase in the magnitude of the cold bias over the southern Amazon. A comparison between WRF temperatures and adjusted temperatures from MERRA (Wang and Zeng 2013) and the daily averages from the CRU TS3.21 product show the same improvement of the temperature bias due to the groundwater scheme (not shown).

On the other hand, the differences in the precipitation fields are not as evident as in the temperature fields. Figure 13 suggests only a small decrease in the dry bias over the southern La Plata basin in the GW simulation. From Table 2 we see that there is a slight decrease in the magnitude of the dry bias over the both the central and southern parts of the La Plata basin. However, the wet bias over the southern Amazon increases.

\section{Summary and discussion}

A sensitivity study of hydrometeorological variables over southern South America to the use of the MMF groundwater scheme in fully coupled land-atmosphere simulations is presented. In general, we find that the groundwater scheme leads to an increase in the simulated soil moisture over those regions where the water table is shallow. In turn, the increase in soil moisture leads to an increase in ET and relative humidity and to a reduction of the LCL and the boundary layer height. During the dry season the groundwater scheme helps to sustain larger values of soil moisture because of a reduction in drainage and even the existence of upward moisture fluxes from the underlying shallow aquifer to the unsaturated soil layers. The extra moisture in the atmosphere (from ET) seems to be linked to an increase in precipitation downstream, where both the current simulations and other regional climate models have a dry bias when compared to observations.

During the early rainy season (October-December) the changes in ET and convective instability are larger than during the dry season. Over parts of the central and southern La Plata the changes in moisture and instability lead to an increase in the simulated convective precipitation. Over the southern extreme of the La Plata region, the cooling effects from the enhanced ET lead to enhanced convective inhibition. Over these regions, however, an increase in rainfall is still observed, but it comes mostly from large-scale precipitation, due to the increase in relative humidity. The regional change in ET and precipitation over the southern La Plata changes 
FD-ERAi_WZ T2M $\left({ }^{\circ} \mathrm{C}\right)$, OND

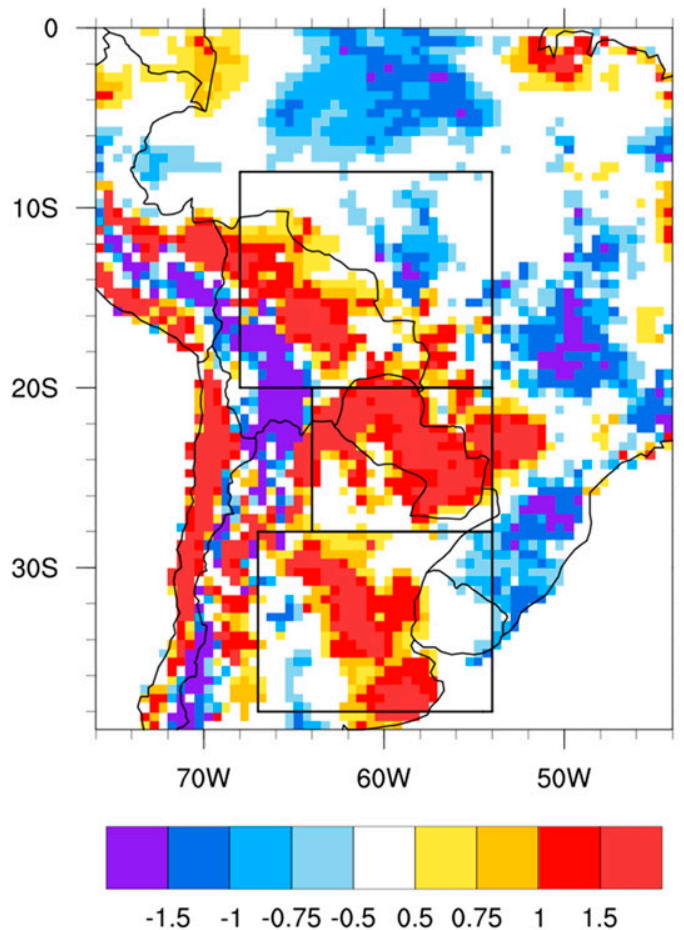

FD-TRMM PCP(mm/day), OND

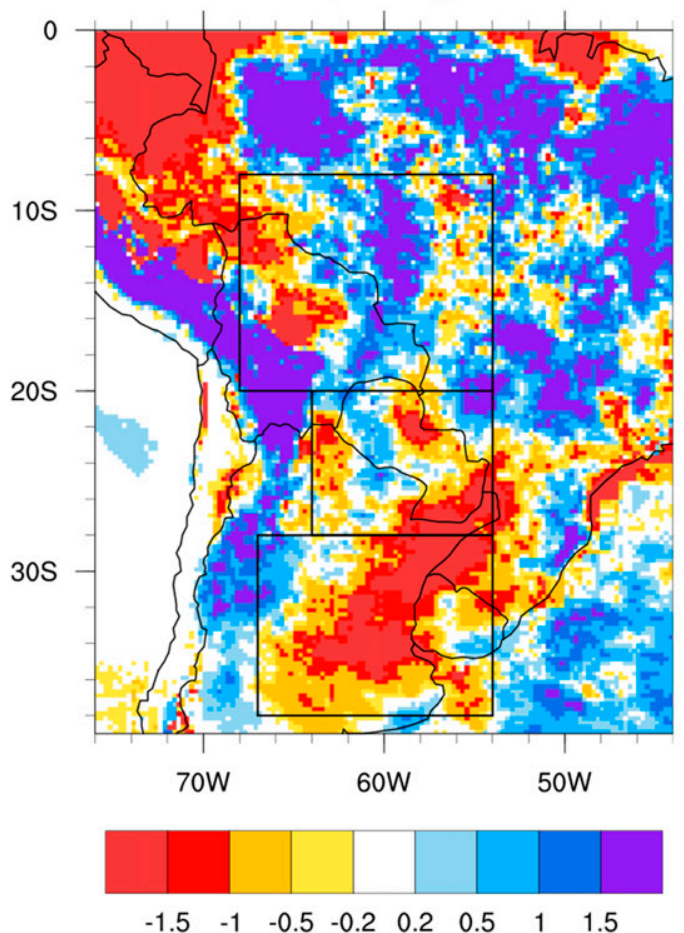

GW-ERAi_WZ T2M $\left({ }^{\circ} \mathrm{C}\right)$, OND

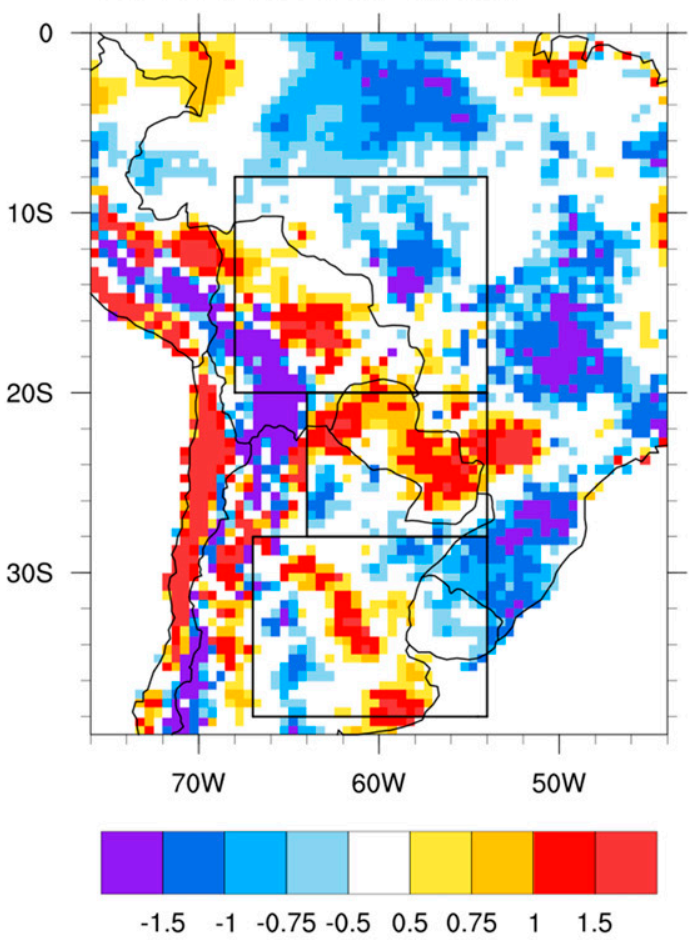

GW-TRMM PCP(mm/day), OND

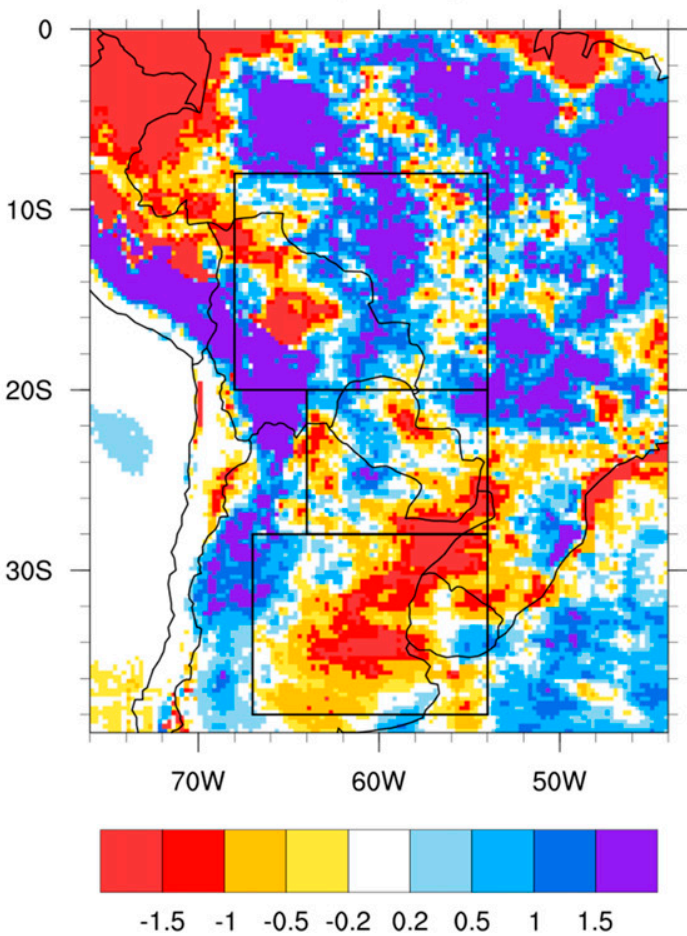

FIG. 13. (top) Difference in near-surface temperature between the ERA-Interim $T_{2 \mathrm{~m}}$ adjusted dataset (Wang and Zeng 2013) and the FD and GW simulations for OND. (bottom) Difference in total precipitation between the TRMM 3B43 dataset and the FD and GW simulations for OND. 
TABLE 2. Area averages of differences between WRF simulations and reference datasets (given in parentheses). $T_{2 \mathrm{~m}}$ is temperature at $2 \mathrm{~m}$ in WRF simulations, TMP is near-surface temperature in the ERA-Interim $T_{2 \mathrm{~m}}$ adjusted dataset (i.e., ERAi_WZ; Wang and Zeng 2013), and $P$ is precipitation.

\begin{tabular}{lrrr}
\hline \hline & & & \\
& LOLP & UPLP & $\begin{array}{c}\text { Southern } \\
\text { Amazon }\end{array}$ \\
\hline$T_{2 \mathrm{~m}(\mathrm{FD})-\mathrm{TMP}\left(\mathrm{ERAi}_{1} \mathrm{WZ}\right)\left({ }^{\circ} \mathrm{C}\right)}$ & 0.51 & 1.09 & 0.11 \\
$T_{2 \mathrm{~m}}(\mathrm{GW})-\mathrm{TMP}(\mathrm{ERAi}+\mathrm{WZ})\left({ }^{\circ} \mathrm{C}\right)$ & -0.01 & 0.43 & -0.20 \\
$P(\mathrm{FD})-P(\mathrm{TRMM})\left(\mathrm{mm} \mathrm{day}^{-1}\right)$ & -0.81 & -0.40 & 0.39 \\
$P(\mathrm{GW})-P(\mathrm{TRMM})\left(\mathrm{mm} \mathrm{day}^{-1}\right)$ & -0.54 & -0.16 & 0.59 \\
\hline
\end{tabular}

from month to month and from year to year, but the use of the groundwater scheme invariably increases the simulated ET and precipitation over the region. The mean regional increase in ET over the southern La Plata is $13 \%$, while the increase in precipitation is $10 \%$, relative to the simulated values without the groundwater scheme. The impact of the groundwater scheme on precipitation is stronger and more spatially homogeneous than that found over North America (Barlage et al. 2015). We also find that the extra precipitation is a larger fraction of the extra ET compared with expected values from the estimated recycling ratios from previous studies. This is additional evidence that suggests that the increase in precipitation when the groundwater scheme is used is due not only to the use of more moisture from local origin (recycling) but also to the effects of this extra moisture on the stability of the atmosphere. Both mechanisms have been described in previous studies (e.g., Schär et al. 1999).

Interestingly the effects of the groundwater scheme were observed during all 4 years of simulation, even with the differences in the regional circulation due to interannual variability (we used spectral nudging). Probably because of this variability, no systematic effects on the winds (i.e., common to all years) were detected, and the most robust effects take place mostly locally (i.e., in the vertical atmospheric column), with some increase in precipitation downstream of the prevailing winds.

The changes in soil moisture and evapotranspiration induced by the groundwater scheme are statistically significant, but this is not the case for other variables. However, the induced changes in temperature, convective available potential energy, and precipitation over the region are of the same order of magnitude as those found in other modeling studies on landatmosphere interactions over southern South America (e.g., Beltrán-Przekurat et al. 2012; Lee and Berbery 2012; Müller et al. 2014), and the overall statistical significance is similar to the results by Beltrán-Przekurat et al. (2012) and Lejeune et al. (2015). This suggests that, although land processes have a detectable effect on the atmosphere, this effect is within the variability of atmospheric variables.

The present sensitivity study attempts to illustrate the potential impacts of a groundwater scheme on the simulation of near-surface conditions and precipitation over southern South America. Therefore, we do not attempt to reduce the biases of the model in the simulation of the regional South American climate: this would require longer simulations than those presented here and a calibration procedure. In the present study, the lack of calibration of the parameters of the MMF scheme could be part of the reason behind the overly deep water table simulated over the La Plata basin. The calibration of the parameters of the MMF scheme would require longterm (several years) estimates of precipitation, ET, and runoff from the model (WRF in our case). Such a calibration procedure was beyond the scope of the present sensitivity study. However, the comparison of the free drainage and groundwater simulations allows for an assessment of the effects of the groundwater scheme on the coupled simulations.

The primary modification of the soil moisture distribution due to the groundwater scheme is not homogeneous, but a result of the estimated effect of the topography and the local climate on the distribution of the water table of shallow unconfined aquifers (Fan et al. 2013). Therefore, the present sensitivity study presents plausible modifications to the simulation of the hydroclimate of southern South America when one of the boundary conditions is changed throughout the simulation, according to a physically based estimation of the shallow aquifers over the region. In contrast, other studies investigate only idealized and/or sensitivity to initial conditions of the soil moisture field (e.g., Schär et al. 1999; Collini et al. 2008; Sörensson and Berbery 2015). The results from the present fully coupled landatmosphere simulations are consistent with results from offline simulations (i.e., with prescribed atmospheric forcing) by Martinez et al. (2016). This means that the increase in ET due to the groundwater scheme observed in the offline simulations is not only preserved in the coupled land-atmosphere simulations, but in addition can affect the near-surface atmospheric conditions and the simulated precipitation patterns. These modifications could be larger, if the water table is actually shallower, as suggested from observations (Fan and Miguez-Macho 2010; Kuppel et al. 2015). This suggests that a calibrated version of the model used in this study, with a more realistic water-table depth distribution, could increase even further the evaporation and precipitation over southern La Plata (see Fig. 12).

The largest sensitivity to the effects of the groundwater scheme are found in parts of the La Plata basin, 
where previous studies have shown a substantial sensitivity of atmospheric conditions, including precipitation, to characteristics and dynamics of the soil moisture field (e.g., Saulo et al. 2010), land-use and land-cover change (Beltrán-Przekurat et al. 2012; Lee and Berbery 2012), land-cover and vegetation properties (Lee et al. 2013; Müller et al. 2014), soil texture properties (e.g., Doyle et al. 2013), and the coupling between soil moisture and precipitation (e.g., Zeng et al. 2010; Sörensson and Menéndez 2011; Spenneman and Saulo 2015). This study, along with other previous studies, suggests that the climate of southern South America is particularly sensitive to surface and subsurface hydrological conditions.

Acknowledgments. We acknowledge the ECMWF for providing the ERA-Interim data used as boundary and initial conditions for the WRF simulations. We also acknowledge the Centre for Environmental Data Archival for providing the CRU TS3.21 data, from their website at http://catalogue.ceda.ac.uk/ uuid/ac4ecbd554d0dd52a9b575d9666dc42d. The TRMM 3B43 data were provided by the Goddard Earth Sciences Data and Information Services Center, through the website http://mirador.gsfc.nasa.gov. Funding for A. Martinez and F. Dominguez comes from NSF AGS 1454089. Funding for G. Miguez-Macho comes from the European Commission FP7 "EartH2Observe" project. We are grateful to James Shuttleworth, Xubin Zeng, and Hoshin Gupta for their insightful comments. We also thank the reviewers for helping to improve the manuscript. This research was supported by NSF Grant 1045260.

\section{REFERENCES}

Anyah, R. O., C. P. Weaver, G. Miguez-Macho, Y. Fan, and A. Robock, 2008: Incorporating water table dynamics in climate modeling: 3. Simulated groundwater influence on coupled land-atmosphere variability. J. Geophys. Res., 113, D07103, doi:10.1029/2007JD009087.

Barlage, M., M. Tewari, F. Chen, G. Miguez-Macho, Z.-L. Yang, and G.-Y. Niu, 2015: The effect of groundwater interaction in North American regional climate simulations with WRF/Noah-MP. Climatic Change, 129, 485-498, doi:10.1007/s10584-014-1308-8.

Beltrán-Przekurat, A., R. A. Pielke Sr., J. L. Eastman, and M. B Coughenour, 2012: Modelling the effects of land-use/landcover changes on the near-surface atmosphere in southern South America. Int. J. Climatol., 32, 1206-1225, doi:10.1002/ joc. 2346 .

Betts, A. K., 2004: Understanding hydrometeorology using global models. Bull. Amer. Meteor. Soc., 85, 1673-1688, doi:10.1175/ BAMS-85-11-1673.

__ 2009: Land-surface-atmosphere coupling in observations and models. J. Adv. Model. Earth Syst., 1, doi:10.3894/ JAMES.2009.1.4.

Chen, J. L., C. R. Wilson, B. D. Tapley, L. Longuevergne, Z. L. Yang, and B. R. Scanlon, 2010: Recent La Plata basin drought conditions observed by satellite gravimetry. J. Geophys. Res., 115, D22108, doi:10.1029/2010JD014689.

Collini, E. A., E. H. Berbery, V. R. Barros, and M. E. Pyle, 2008: How does soil moisture influence the early stages of the South American monsoon? J. Climate, 21, 195-213, doi:10.1175/ 2007JCLI1846.1.

Cotton, W. R., and R. A. Pielke Sr., 2007: Human Impacts on Weather and Climate. Cambridge University Press, 332 pp.

de Goncalves, L. G. G., W. J. Shuttleworth, E. J. Burke, P. Houser, D. L. Toll, M. Rodell, and K. Arsenault, 2006a: Toward a South American land data assimilation system: Aspects of land surface model spin-up using the Simplified Simple Biosphere. J. Geophys. Res., 111, D17110, doi:10.1029/2005JD006297.

,-- S. C. Chou, Y. Xue, P. R. Houser, D. L. Toll, J. Marengo, and M. Rodell, 2006b: Impact of different initial soil moisture fields on Eta Model weather forecasts for South America. J. Geophys. Res., 111, D17102, doi:10.1029/2005JD006309.

Dirmeyer, P. A., K. L. Brubaker, and T. DelSole, 2009a: Import and export of atmospheric water vapor between nations. J. Hydrol., 365, 11-22, doi:10.1016/j.jhydrol.2008.11.016.

- C. A. Schlosser, and K. L. Brubaker, 2009b: Precipitation, recycling, and land memory: An integrated analysis. J. Hydrometeor., 10, 278-288, doi:10.1175/2008JHM1016.1.

Doyle, M. E., J. Tomasella, D. A. Rodríguez, and S. C. Chou, 2013: Experiments using new initial soil moisture conditions and soil map in the Eta Model over La Plata basin. Meteor. Atmos. Phys., 121, 119-136, doi:10.1007/s00703-013-0265-5.

Fan, Y., 2015: Groundwater in the Earth's critical zone: Relevance to large-scale patterns and processes. Water Resour. Res., 51, 3052-3069, doi:10.1002/2015WR017037.

, and G. Miguez-Macho, 2010: Potential groundwater contribution to Amazon evapotranspiration. Hydrol. Earth Syst. Sci., 14, 2039-2056, doi:10.5194/hess-14-2039-2010.

- H. Li, and G. Miguez-Macho, 2013: Global patterns of groundwater table depth. Science, 339, 940-943, doi:10.1126/ science.1229881.

Findell, K. L., and E. A. B. Eltahir, 2003: Atmospheric controls on soil moisture-boundary layer interactions. Part II: Feedbacks within the continental United States. J. Hydrometeor., 4, 570-583, doi:10.1175/1525-7541(2003)004<0570:ACOSML>2.0.CO;2.

Fisher, J. B., and Coauthors, 2009: The land-atmosphere water flux in the tropics. Global Change Biol., 15, 2694-2714, doi:10.1111/ j.1365-2486.2008.01813.x.

Huffman, G. J., and D. T. Bolvin, 2014: TRMM and other data precipitation data set documentation. NASA TRMM Doc., $42 \mathrm{pp}$. [Available online at ftp://precip.gsfc.nasa.gov/pub/ trmmdocs/3B42_3B43_doc.pdf.]

, and Coauthors, 2007: The TRMM Multisatellite Precipitation Analysis (TMPA): Quasi-global, multiyear, combined-sensor precipitation estimates at fine scales. J. Hydrometeor., 8, 38-55, doi:10.1175/JHM560.1.

Jiang, X., G.-Y. Niu, and Z.-L. Yang, 2009: Impacts of vegetation and groundwater dynamics on warm season precipitation over the central United States. J. Geophys. Res., 114, D06109, doi:10.1029/2008JD010756.

Jones, P. D., and I. Harris, 2013: CRU TS3.21: Climatic Research Unit (CRU) Time-Series (TS) version 3.21 of high resolution gridded data of month-by-month variation in climate (Jan. 1901-Dec. 2012). NCAS British Atmospheric Data Centre, accessed 26 July 2016, doi:10.5285/ D0E1585D-3417-485F-87AE-4FCECF10A992.

Koirala, S., P. J.-F. Yeh, Y. Hirabayashi, S. Kanae, and T. Oki, 2014: Global-scale land surface hydrologic modeling with the 
representation of water table dynamics. J. Geophys. Res. Atmos., 119, 75-89, doi:10.1002/2013JD020398.

Kuppel, S., J. Houspanossian, M. D. Nosetto, and E. G. Jobbágy, 2015: What does it take to flood the Pampas?: Lessons from a decade of strong hydrological fluctuations. Water Resour. Res., 51, 2937-2950, doi:10.1002/2015WR016966.

Lee, S.-J., 2010: Impact of land surface vegetation change over the La Plata basin on the regional climatic environment: A study using conventional land-cover/land-use and newly developed ecosystem functional types. Ph.D. dissertation, University of Maryland, College Park, 153 pp. [Available online at http://hdl.handle.net/1903/10831.]

— climate of the La Plata basin. J. Hydrometeor., 13, 84-102, doi:10.1175/JHM-D-11-021.1.

,-- , and D. Alcaraz-Segura, 2013: The impact of ecosystem functional type changes on the La Plata basin climate. $A d v$. Atmos. Sci., 30, 1387-1405, doi:10.1007/s00376-012-2149-x.

Lejeune, Q., E. D. Davin, B. P. Guillod, and S. I. Seneviratne, 2015: Influence of Amazonian deforestation on the future evolution of regional surface fluxes, circulation, surface temperature and precipitation. Climate Dyn., 44, 2769-2786, doi:10.1007/s00382-014-2203-8.

Martinez, J. A., and F. Dominguez, 2014: Sources of atmospheric moisture for the La Plata River basin. J. Climate, 27, 67376753, doi:10.1175/JCLI-D-14-00022.1.

- _ - and G. Miguez-Macho, 2016: Effects of a groundwater scheme on the simulation of soil moisture and evapotranspiration over southern South America. J. Hydrometeor., 17, 2941-2957, doi:10.1175/JHM-D-16-0051.1.

Miguez-Macho, G., and Y. Fan, 2012: The role of groundwater in the Amazon water cycle: 2. Influence on seasonal soil moisture and evapotranspiration. J. Geophys. Res., 117, D15114, doi:10.1029/2012JD017540.

, G. L. Stenchikov, and A. Robock, 2004: Spectral nudging to eliminate the effects of domain position and geometry in regional climate model simulations. J. Geophys. Res., 109, D13104, doi:10.1029/2003JD004495.

_- Y. Fan, C. P. Weaver, R. Walko, and A. Robock, 2007: Incorporating water table dynamics in climate modeling: 2. Formulation, validation, and soil moisture simulation. J. Geophys. Res., 112, D13108, doi:10.1029/2006JD008112.

Müller, O. V., E. H. Berbery, D. Alcaraz-Segura, and M. B. Ek, 2014: Regional model simulations of the 2008 drought in South America using a consistent set of land surface properties. J. Climate, 27, 6754-6778, doi:10.1175/JCLI-D-13-00463.1.

Niu, G.-Y., Z.-L. Yang, R. E. Dickinson, L. E. Gulden, and H. Su, 2007: Development of a simple groundwater model for use in climate models and evaluation with Gravity Recovery and Climate Experiment data. J. Geophys. Res., 112, D07103, doi:10.1029/2006JD007522.

, and Coauthors, 2011: The community Noah land surface model with multiparameterization options (Noah-MP): 1 . Model description and evaluation with local-scale measurements. J. Geophys. Res., 116, D12109, doi:10.1029/2010JD015139.
Pan, Z., E. Takle, M. Segal, and R. Turner, 1996: Influences of model parameterization schemes on the response of rainfall to soil moisture in the central United States. Mon. Wea. Rev., 124, 1786-1802, doi:10.1175/1520-0493(1996)124<1786: IOMPSO $>2.0 . \mathrm{CO} ; 2$.

Pielke, R. A., Sr., 2001: Influence of the spatial distribution of vegetation and soils on the prediction of cumulus convective rainfall. Rev. Geophys., 39, 151-177, doi:10.1029/1999RG000072.

Ruiz, J. J., C. Saulo, and J. Nogués-Paegle, 2010: WRF model sensitivity to choice of parameterization over South America: Validation against surface variables. Mon. Wea. Rev., 138, 3342-3355, doi:10.1175/2010MWR3358.1.

Saulo, C., L. Ferreira, J. Nogués-Paegle, M. Seluchi, and J. Ruiz, 2010: Land-atmosphere interactions during a northwestern Argentina low event. Mon. Wea. Rev., 138, 2481-2498, doi:10.1175/2010MWR3227.1.

Schär, C., D. Lüthi, and U. Beyerle, 1999: The soil-precipitation feedback: A process study with a regional climate model. J. Climate, 12, 722-741, doi:10.1175/1520-0442(1999)012<0722: TSPFAP $>2.0 . C O ; 2$.

Seneviratne, S. I., T. Corti, E. L. Davin, M. Hirschi, E. B. Jaeger, I. Lehner, B. Orlowsky, and A. J. Teuling, 2010: Investigating soil moisture-climate interactions in a changing climate: A review. Earth Sci. Rev., 99, 125-161, doi:10.1016/ j.earscirev.2010.02.004.

Skamarock, W. C., and Coauthors, 2008: A description of the Advanced Research WRF version 3. NCAR Tech. Note NCAR/TN-475+STR, 113 pp., doi:10.5065/D68S4MVH.

Solman, S. A., and N. L. Pessacg, 2012: Regional climate simulations over South America: Sensitivity to model physics and to the treatment of lateral boundary conditions using the MM5 model. Climate Dyn., 38, 281-300, doi:10.1007/s00382-011-1049-6.

_ - and Coauthors, 2013: Evaluation of an ensemble of regional climate model simulations over South America driven by the ERA-Interim reanalysis: Model performance and uncertainties. Climate Dyn., 41, 1139-1157, doi:10.1007/ s00382-013-1667-2.

Sörensson, A. A., and C. G. Menéndez, 2011: Summer soilprecipitation coupling in South America. Tellus, 63A, 56-68, doi:10.1111/j.1600-0870.2010.00468.x.

— , and E. H. Berbery, 2015: A note on soil moisture memory and interactions with surface climate for different vegetation types in the La Plata basin. J. Hydrometeor., 16, 716-729, doi:10.1175/JHM-D-14-0102.1.

Spenneman, P. C., and A. C. Saulo, 2015: An estimation of the land-atmosphere coupling strength in South America using the Global Land Data Assimilation System. Int. J. Climatol., 35, 4151-4166, doi:10.1002/joc.4274.

Wang, A., and X. Zeng, 2013: Development of global hourly $0.5^{\circ}$ land surface air temperature datasets. J. Climate, 26, 76767691, doi:10.1175/JCLI-D-12-00682.1.

Zeng, X., M. Barlage, C. Castro, and K. Fling, 2010: Comparison of land-precipitation coupling strength using observations and models. J. Hydrometeor., 11, 979-994, doi:10.1175/ 2010JHM1226.1. 